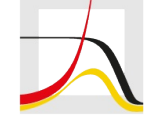

MAX PLANCK INSTITUTE

FOR DEMOGRAPHIC RESEARCH

Konrad-Zuse-Strasse 1 · D-18057 Rostock · Germany · Tel +49 (0) 3812081 - 0 · Fax +49 (0) 3812081 - $202 \cdot$ www.demogr.mpg.de

MPIDR Working Paper WP 2022-004 I January 2022

https://doi.org/10.4054/MPIDR-WP-2022-004

\title{
A gender story of social disengagement of young adults in Latin America
}

\author{
Chia Liu \\ Andrés F. Castro Torres I castro@demogr.mpg.de \\ Ewa Batyra
}

This working paper has been approved for release by: Peter Eibich (eibich@demogr.mpg.de),

Deputy Head of the Research Group Labor Demography.

(c) Copyright is held by the authors.

Working papers of the Max Planck Institute for Demographic Research receive only limited review. Views or opinions expressed in working papers are attributable to the authors and do not necessarily reflect those of the Institute. 


\title{
Title
}

A gender story of social disengagement of young adults in Latin America

\begin{abstract}
In the recent years, Latin America has seen a large number of young adults who are neither engaged in formal education nor work, commonly dubbed as "nini" ( " $i$ " trabajan "ni" estudian). This study tests the role household structure plays on becoming a nini in 12 Latin American countries. We explore the gender dynamic of human capital stagnation and intergenerational mobility by focusing on early family formation for women and men aged 2025 using censuses from the Integrated Public-Use Microdata Series (IPUMS-I). Countryspecific linear regression models reveal that the intersection of class and gender is a major determinant of labor force and educational disengagement in the region. Women from lower social origin who leave parental home to enter union and parenthood at younger ages are particularly disadvantaged. Moreover, among those who are active in the labor market, young mothers are less likely to experience upward intergenerational mobility in occupation compared to those who delay childbearing. This work highlights the importance of addressing economic and educational disengagement of early adulthood to foster economic growth and development in the region.
\end{abstract}

\section{Keywords}

Latin America, gender, family, labor force, early parenthood, adolescent 


\section{Introduction}

A high proportion of young adults in Latin America and the Caribbean (LAC) are neither in work (" $i$ " trabajan) nor in school (" $i$ " estudian), opening a line of research aimed at identifying the root causes of early human capital disengagement (Navarrete Lopez \& Padron Innamorato, 2021). Nearly one out of five youths between the ages of 15 to 24 in LAC are estimated to be what has been dubbed "nini" (De Hoyos et al., 2016). The nini population is a cause for concern over several issues. On the individual level, educational and economic disengagement at young ages adversely affect lifetime earnings and occupational opportunities (Amarante et al., 2017), leading to a heightened risk of economic vulnerability and social marginalization. On the societal level, untapped human resources, and failure to harness productivity stifle regional economic growth, which further limits the development of structural opportunities. Limited upward mobility and unmet basic needs fuel social unrest, which has extensively plagued the region in the recent years (Sánchez-Ancochea, 2021).

One alarming aspect of the nini phenomenon is its gender imbalance, or the high propensity for women to disengage in education and work at young ages. Although family and labor force participation are often highly interrelated for young women everywhere, including in societies with comprehensive social safety nets and egalitarian policies (Gangl \& Ziefle, 2009), it is of particular interest in LAC. The region holds several attributes that in combination sets it apart from the rest of the world: high levels of single motherhood and union instability (Esteve, Lesthaeghe, et al., 2012; Liu et al, 2017; Socolow, 2015), limited social mobility (Azevedo \& Bouillon, 2010; Behrman et al., 2001; Blanden, 2009; Torche, 2014), and less refined public welfare systems compared to wealthier regions (Gough, 2010). These characteristics of LAC in combination with female early labor market detachment place women and their offspring on a path of disadvantage which carries long-term repercussions for both generations. 
Extensive work has addressed gender economic inequality in LAC, through investigating gender wage gap (e.g. Angel-Urdinola \& Wodon, 2006; Ben Yahmed, 2018; Nopo \& Hoyos, 2010), occupational barriers (Klasen, 2019), and female labor force participation (Busso \& Fonseca, 2015). These studies often pinpoint the primary factor that stalls women's labor market activities: starting her own conjugal family. Once having formed a partnership, women invest more time to care work and household chores than men, particularly following childbirth, decreasing their capacity for labor market work (Amarante \& Rossel, 2018; Busso \& Fonseca, 2015; Urdinola \& Tovar, 2019), although highly educated women are more likely to remain in the labor market (Chioda, 2011; Gasparini et al., 2015). Overall, early entrance into motherhood entails foregone human capital accumulation, which is deleterious toward lifetime earnings, particularly for disadvantaged groups (Chioda, 2011; Miller, 2009).

A wealth of literature highlight gender specialization of market and household work among couples in Western, higher-income societies, under the context of marriage and stable unions (Becker, 1993; Oppenheimer, 1997; Özcan \& Breen, 2012). We argue that the processes associated with women's human capital accumulation and employment upon entering adulthood in LAC require a different lens due to the region's remarkably high union instability, and as a result, pervasive single motherhood (Esteve, García-Román, et al., 2012). Under the context of universal marriage and union stability, gender specialization in market and household work starts from a baseline of shared resources among the conjugal partners, particularly in childrearing. Without such context, early departure from school or labor market inactivity due to partnership formation and/or childbearing place women and their children in severe economic insecurity should the union dissolve.

Quantifying the level of labor market engagement comes with unique challenges for LAC due to its extensive underground economy, upheld by individuals who work informally. In the recent years, the notion of nini sparked controversy among scholars, with opponents citing the 
inaccuracy of referring to women who are rearing children as inactive (Assusa, 2019; Santillan Pizarro \& Pereyra, 2020). In fact, when one excludes young mothers from such definition, the number of nini's plummets from eight to just over one million, most of whom are men (Assusa, 2019; Leyva \& Negrete, 2014). Some studies propose to exclude women in the nini universe, or simply consider them as being "temporary nini" while they are under care work obligations (e.g. Paz, 2021). We argue against this framework of traditional gender division of work, particularly in the context of LAC where union instability is high, where household-level wellbeing does not necessarily translate into individual benefit in the long term. The perspective of institutional disengagement therefore requires the consideration of socioeconomic inequality and family situations as individuals transition to adulthood, i.e., form unions, have children or experience separation.

Our study focuses on life course disadvantage in the LAC region by addressing those aged between 20 to 25 who do not participate in formal education nor labor market across 12 countries in LAC using censuses from the Integrated Public-Use Microdata Series (IPUMS-I). We propose a comprehensive view of disengagement in both the labor market and education in young adulthood, by exploring how it is related to young adults' family situation and how it differs by gender and social origin. First, we explore the extent to which young adults are neither in education of formal work. Second, for those who work, we examine their upward intergenerational mobility in occupation compared to their coresidential parent(s).

This work contributes to the literature on gender disparity in human capital accumulation in early life stages, which leads to further bifurcation of men and women's opportunity structures over the life course (Deere \& Leon, 2003). Not only can gender contribute to diverging family and work pathways, the lack of mobility or engagement in the public sphere in general expose men and women to different sets of risks. For women, the extension of gender wage gap leads to a gender pension gap (CEPAL, 2019), due to women's lower labor force participation with 
more extended interruptions in working life, which can result in later life precarity (Amarante et al., 2017). Additionally, for single mothers who are not working nor studying, the double load of economic strain and childrearing responsibilities expose both mother and child(ren) to economic uncertainty. For men, in some places, such as Mexico-US border, early drop-out of school and failure to enter gainful employment often puts young adults at an elevated risk of involvement in gangs and criminal activities (De Hoyos \& Gutiérrez Fierros, 2017) lowering life expectancy for men (Canudas-Romo \& Aburto, 2019) on the individual level, while introducing crime and insecurity on the regional level .

It is important to note that because our data cannot accurately capture informal work, we define inactivity as non-participation in the formal institutions of education and work (simply noted as "inactivity" hereon for simplicity). This also implies that, the observed prevalence of ninihood among socioeconomically vulnerable households, is likely to signal a double burden: lack of social protection and long-term financial vulnerability, on the one hand, and low-paid, unstable, sometimes exploitative working conditions in the informal economy, on the other (Portes \& Hoffman, 2003). Apart from paying particular attention to these conceptual and measurement challenges when describing and discussing our results, our approach carries several strengths. First, the harmonized census datasets across LAC countries allow us to draw cross-national comparisons to provide a broad regional overview. Second, extensive family information can be inferred from household level census data, such as family composition and early parenthood. Lastly, the data facilitates the examination of household structure, the timing of parenthood, and occupation for both the parental generation and the young adult's generation. Using this analytical strategy, we are able to identify the household structure and social mobility between the parent-child generations. To our knowledge, no study has tested the relationship between both work and educational inactivity and occupational mobility by 
household structure, particularly early partnership and parenthood, from a cross-national perspective in LAC.

\section{Background}

\section{Inactivity: NiNi (a.k.a. NEET)}

Young adults in LAC who do not work nor study are commonly referred to as "nini" (" $n i$ estudian ni trabajan", or "neither work nor study") (De Hoyos et al, 2016; De Hoyos \& Gutiérrez Fierros, 2017) or sometimes NEET ("not in education, employment or training"). Globally, higher income countries, such as Sweden and Luxembourg, tend to have lower percentage of ninis, hovering between 4 to 5 percent of all young adults, while Iraq, Guyana, and Nigeria have the highest incidence of ninis at a striking 43 to 51 percent (De Hoyos et al., 2016). Although LAC shows a similar percentage of ninis as the global average, around 22.4 percent, the percentage of ninis is particularly high in Central America. Due to population sizes, the largest numbers of ninis in the region can be found in Brazil and Colombia (De Hoyos et al., 2016). The vast majority (76\%) of ninis are women, which juxtapose against overall higher female representation in secondary school enrolment and completion in the region (PAHO, 2018).

The gender disparity in the propensity of early nini-hood is often attributed to the family formation process, after which informal household related tasks tend to be assigned to or taken on by women (Amarante et al., 2017; PAHO, 2018). Household composition, in particular, the presence of a partner and younger children, contributes to economic activity for men and inactivity for women in regions that hold pervasive male breadwinner ideology (Staab, 2012). Overall, the gender gap in labor force participation in LAC has slightly converged from 1990 to 2010 , with $40.7 \%$ women and $82.5 \%$ men working in 1990 and $52.6 \%$ women and $79.6 \%$ men in 2010. The participation gap between women and men in the recent years is notably 
larger in Central American countries such as Mexico (43.4\% versus $80.6 \%$ for women and men respectively) and Honduras (43.3\% and 81.6\%), compared to Bolivia (61.6\% and 82\%) and Peru $(66.8 \%$ and $83.4 \%)$ (ILO, 2013).

LAC saw an impressive rise in female labor force participation (FLFP) from the 90s to 2010s, but has since experienced a deceleration in the recent years, with a growth of $0.2 \%$ between the 2005 to 2012, down from $0.81 \%$ between 1992 to 2005 (Gasparini et al., 2015). Gasparini and colleagues find that several conditions are positively associated with women's market work, such as living in urban areas, being highly educated, and being single. Some situations, such as being married to a high earner, stipulate multiple opposing influences on women's participation such as that wives of high earners have lower economic needs to work but tend to be highly educated herself.

Among working individuals, previous studies have revealed gender disparity in the labor market in LAC, such as in the form of gender wage gap (e.g. Ben Yahmed, 2018; Nopo \& Hoyos, 2010). Paradoxically, disparity increased with factors that were expected to level the playing field for women, such as the introduction of new labor regulations aimed to protect women inadvertently led to some companies' reluctance to hire women (Angel-Urdinola \& Wodon, 2006). As years of schooling for women increase, tighter gender gate-keeping in decision-making positions (Camou \& Maubrigades, 2017) and occupational barriers (Klasen, 2019) are speculated to have led to only a modest comparative wage improvement for women. Other aspects of gender disparity in the labor market, such as inactivity in young adulthood and intergenerational mobility, are far less studied.

Measuring labor market inactivity in LAC is complex, due to a large number of individuals, mostly women, working in informal sectors (ILO, 2013). However, previous work which target a selected number of LAC countries, namely, Argentina, Brazil, Peru, Chile, and Mexico, point 
to the fact that informal jobs are often taken on by mothers who are unable to juggle inflexible formal work alongside household and childcare responsibilities, and these jobs offer little social protection and may expose women to abuse and exploitation (Casanova, 2019; Chanel \& Garcia Castro, 1989; Villanueva \& Lin, 2020). Informality of work is often associated with unskilled labor, lower wages, and a diminishing probability of ever moving into the formal labor market (Gong \& van Soest, 2002). The severe penalty of invisibility in the labor market, carries repercussions that are akin to being entirely absent from the labor market.

Overall, women's engagement in the labor market fluctuates across the life course by both macroeconomic conditions, such as labor supply demand in female-dominant industries, and microeconomic or individual-level situations, exemplified by early parenthood. For those who temporarily exit from the formal labor market at critical work ages due to family obligations, playing catch up can be difficult later on even if individuals were able to return to work after a prolonged disengagement spell. Despite having experienced substantial educational expansion in the recent years, LAC has seen limited changes in early partnership and childbearing, a linkage found in other parts of the world (Caffe et al., 2017; Esteve, Lesthaeghe, et al., 2012; Esteve \& Florez-Paredes, 2018).

\section{Family in Latin America}

A key contributor to gender inequality in labor market outcomes is the high levels of adolescent birth rate in LAC (Conde-Agudelo et al., 2005; Dongarwar \& Salihu, 2019), especially in poorer and rural communities (Neal et al., 2018). Central American and the Caribbean see the highest numbers of single-mother and female headed households (Caffe et al., 2017; Gindling \& Oviedo, 2008; Liu et al., 2017). Women not only tend to be the primary caretaker of their own children (and sometimes of other family members), but they also leave parental home and/or form union at younger ages, all of which require them to weather more uncertainties, 
particularly in the event of union dissolution, compared to young adults who remain in their parental home.

The pervasiveness of intergenerational coresidence is another salient characteristic of Latin American families (Ruggles \& Heggeness, 2008). Nearly 70\% of single mothers in LAC live with their own parents (Esteve \& Florez-Paredes, 2018b), showing that interfamilial exchanges serve as a vital safety net for those in vulnerable positions. Delayed nest leaving, or prompt nest returning, can be the result of young adults' need for housing or (grand)parental care in times of hardship such as job loss, housing shortage, or early childbearing (Aragao \& Villanueva, 2021; Galambos \& Martínez, 2007; Ruggles \& Heggeness, 2008). In the case of young mothers, living with other kin, who presumably provide some childcare, increases their probability to engage in the labor market (Aragao \& Villanueva, 2021). On the other hand, for the more privileged, intergenerational coresidence can facilitate prolonged education of the younger generation, often under the context of delayed union formation and parenthood (Galambos \& Martínez, 2007). This period of "emerging adulthood" allows the young to accumulate human capital geared toward future higher earnings (Juárez \& Gayet, 2014). The pervasiveness of intergenerational households in the region also offers researchers a unique opportunity to observe intergenerational occupational mobility using cross-sectional data such as the censuses.

\section{Research Aims}

This study sheds light on the extent to which early partnership and parenthood are associated with institutional disengagement, or becoming a nini, by gender and social class. Following previous critiques to the understanding of nini-hood, we recognize that this notion of institutional disengagement is partial because the so-called ninis participate in several social institutions (e.g., the family and local organizations). It refers to formal labor force participation and education, which do not include (re)productive activities and learning processes occurring 
outside of the formal economy and the national educational systems. We take a holistic view of the family by including those who are potentially providers or dependents, by looking at multiple generations and the presence of one's own conjugal family, considering that not all those who live with parents do so under the same circumstances. We stratify individuals by social class, operationalized as the education level of the household head, to detect whether the disadvantage associated with early parenthood is moderated by one's social class. To take the analyses one step further, we scrutinize working individuals' occupational mobility compared to their coresidential parents to examine the potential links between early departure from education and work on social (im)mobility. We also investigate country-level differences to highlight regional heterogeneity.

\section{Data}

We use the harmonized samples of the population and housing censuses from the Integrated Public Use Microdata Series (IPUMS-I) (Minnesota Population Center, 2020). The main advantages of IPUMS-I data include large samples (10\% of the population of each country) and wide geographical coverage. We rely on the most recent census for each of the 12 countries: Brazil, Costa Rica, Dominican Republic, Ecuador, El Salvador, Guatemala, Honduras, Mexico, Nicaragua, Panama, Paraguay, and Peru (sample size shown in Table 1). IPUMS-I data provide a wide range of variables necessary for our analysis such as educational and work status, union status, household structure, place of residence, homeownership and, for young adults living with parents, parental characteristics. Bolivia, Colombia, Haiti, and Chile are excluded from the final analyses due to data incompatibility (e.g., high proportion of missing information on key variables).

We focus on young adults, or women and men aged 20 to 25 at the time of the census. Using information on the educational and work status of young adults, we identify whether they 
engage in unpaid work, paid work, combine work and school, attend school only, or none of the above (nini). Those who are unemployed but are actively searching for a job are not part of the nini universe.

One of the most remarkable attributes of the IPUMS-I is that individuals are organized into their households. The Constructed Family Interrelationships variable allows us to define three out of the four key variables that we use to explore the determinants of young adults' educational-work status. First, we define the structure of the household that young adults live in, using the following grouping: (i) nuclear (young adult living with both parents), (ii) singleparent (young adult living with one parent), (iii) nuclear-own (young adult living with their partner with or without children), (iv) single-parent own (young adult living without a partner and with their child), (v) extended (young adult living with parent(s) and more relatives), (vi) composite (more than one nuclear unit of people who are not necessarily related). All other household types that we could not classify as one of the abovementioned categories are grouped into (vii) other. Second, having identified whether there are any children of young adults living in a household and using the information about the age of these children, we classify individuals according to their parenthood status and the age at which they became parents. We group young adults into those who have no children, who became parents as teenagers (19 or younger, referred to as "teenage parents") and those who became parents between age 20 and 24 (referred to as "young parents"). Third, we identify the level of education of the household head-less than primary education, primary education completed, and some secondary education or more-and use it as a proxy for the young adult's social class. Although educational attainment may not be a good proxy for social class in all contexts (e.g., high income countries), it is a useful measure of individuals' social position for this study given the historical lack of universal coverage of LAC educational systems and modest enrolment rates at higher levels. This is particularly true for the household heads in our sample, generally born 
before 1980, who did not fully benefit from the educational expansion as reflected in their educational attainment profiles (see Appendix). Finally, utilizing the information on union status, we group young adults into those who are unpartnered, in a cohabiting union (abbreviated as "in union" in figures and tables), or married.

We consider the young adults' place of residence (urban or rural) and their homeownership status (renting, owning, or neither). These two latter variables account for macro- and microlevel socioeconomic disparities that may affect individuals' institutional disengagement, respectively. Opportunities of formal employment and high-quality education are scarcer in rural than urban areas. Well-paid jobs, secondary, and higher education institutions are concentrated in urban areas. Homeowners and renters are typically better off socioeconomically compared to families that neither own nor rent a home. These families typically occupy housing in exchange for work or surveillance of a larger property. This type of informal arrangements is characteristic of rural areas and expose occupiers to vulnerability due to its informal nature and the lack of institutional regulations. In urban areas, poor families simply occupy territories, forming slums (barrios de invasion, invasions, barrios ilegales), and are permanently at risk of being evacuated by the authorities (Ward et al., 2015).

While the abovementioned information is available for all individuals aged 20 to 25 , the occupation status of parents of the young adults, which is necessary for the analysis of intergenerational mobility, can be identified only for those individuals who still live with their parents. Because of this limitation, for the study of occupational mobility, we focus on subsamples of young adults living with their parents to capture two generations. Our analyses align with earlier studies which showed that a large proportion of young adults in Latin America coreside with parents (Ruggles \& Heggeness, 2008). The total number of individuals aged 20 to 25 who live with and without their parents is displayed in Table 1 . Overall, more than $50 \%$ of the individuals are linked to their parents. The low percentage of individuals with ambiguous 
links to their parents (1.6 percent) speaks to the quality of the IPUMS-I family Constructed variables and give us confidence on the constructed kinship links in the analytical sample. The other half of young adults live in separate households and therefore cannot be linked. We examine the characteristics of those who do not live with their parents in the same age group to understand potential biases resulting from the choice of subsamples for the mobility analys is (results are shown in Appendix, Table A2).

$* * *$ Table 1 here $* * *$

To define our outcome related to occupational intergenerational mobility, we use information on an individual's and their parents' occupation (according to the International Standard Classification of Occupations, ISCO ${ }^{1}$ ). The main advantage of the ISCO classification is that we can rank occupational categories according to standard scales of prestige (Ganzeboom \& Treiman, 1996). To construct our measures of intergenerational mobility, we recode the occupation of individuals as "upwardly mobile" if they are in higher-rank occupations than their parents.

\section{Methods}

We rely on country-specific linear models with the Poisson distribution and the log as a link, and run a series of regressions, focusing on the three outcomes separately: (i) inactivity (nini), (ii) employment (in work), (iii) occupational upward mobility. We chose this model because the coefficients correspond to relative gaps between target and reference categories in the $\log$ scale. The $\log$ scale is preferred due to its symmetry. Additionally, marginal predicted

\footnotetext{
${ }^{1}$ From the lowest to the highest ranked, the harmonized ISCO categories are the following: elementary occupations; plant and machine operators and assemblers; crafts and related trades workers; skilled agricultural and fishery workers; service workers and shop and market sales; clerks; technicians and as sociate profes sionals; professionals; legislators, senior officials, and managers. We excluded records with missing information and individuals working for the armed forces.
} 
probabilities can be easily retrieved by taking the exponentiated of the coefficients. The model is defined as follows (Dobson \& Barnett, 2008):

$$
E\left(Y_{i}\right)=\mu_{i}=n_{i} e^{\mathbf{x}_{i}^{T} \boldsymbol{\beta}} ; \quad Y_{i} \sim \text { Poisson }\left(\mu_{i}\right)
$$

Yi is the number of individuals in each category of one of our three outcomes ('Nini', 'In work,' and 'Upwardly mobile') and the $i^{\text {th }}$ variation pattern, $\mathrm{X}_{i}$ is a vector with the $i^{\text {th }}$ variation pattern across explanatory and control variables, $\beta$ a vector of coefficients, and $\mathrm{n}_{i}$ is the total number of individuals in the $i^{\text {th }}$ variation pattern. The main explanatory variables are young adults' household structure, parenthood, partnership status, and social class (proxied with household head's education level). In all models, we control for young adult's age, place of residence, and homeownership. In the first step, we run separate models for women and men to explore gender dynamics of young adults' educational-occupational status and the propensity of upward mobility. We plot all country-specific coefficients, and we report country-specific intercepts for guidance on the absolute value of the relative gaps.

We subsequently stratify our analyses by our measure of social class to further explore the intersection between social position, gender, and family circumstances. Because this stratification involves 36 fitted models (country-educational attainment combinations), we illustrate these results using predicted proportions. Predicted proportions are useful for crossnational comparisons because they do not require 36 intercepts of the fitted models to be shown (full tables with model estimates are available upon request).

\section{Results}

School and Work Disengagement: A Source of Vulnerability Among Young Adult Women

Figure 1 displays the distribution of young adults according to their employment and school attendance profiles, with dashed vertical lines dividing proportion into quarters to ease 
interpretation, and countries labelled using the first three letters of their names. Central American nations (Guatemala, Honduras, Nicaragua, and El Salvador) stand out by their high proportion of women that are not attending school nor working (nini-hood $>50 \%$ ). Mexico and South American nations display intermediate levels of nini-hood among women, and the lowest levels are observed in the two Caribbean nations of the sample (Costa Rica and the Dominican Republic) and Brazil. A small proportion of individuals, identified as "unpaid worker", work in uncompensated but non-family related tasks, such as farm or domestic help. These regional differences speak to the heterogeneity of the nini phenomena in the region which requires country-specific analyses.

$* * *$ Figure 1 here $* * *$

Three gender-related patterns are common among these 12 countries. First, joint disengagement from formal education and work is more prevalent among women than men. Even in the Dominican Republic, the country with the lowest proportion of women in the 'nini' category, women are 1.7 times more likely to be 'nini' than men (i.e., $28 \%$ vs. $17 \%$ ). Second, men are substantially more likely to be 'In work' compared to women. Third, women are more likely to be exclusively attending school or working and attending school simultaneously than men.

Figure 2 shows the results of the country-specific regression models that predict the proportion of individuals in the 'nini' category. The regression coefficients suggest that there are stark gender differences in the relationship between household type and the school and labor market disengagement.

*** Figure 2 here $* * *$

In contrast to the cross-national differences in the prevalence of nini-hood among women displayed in Figure 1, country-specific intercepts are more homogeneous (included next to the 
country names in the label). These model's intercepts imply predicted proportions of nini-hood, e.g. between $\exp (-2.0)=0.13$ (Panama) and $\exp (-1.1)=0.33$ (Honduras) for the reference categories of the explanatory variables (i.e., for normative family circumstances among young adults, refer to Table A1). In addition, these predicted proportions are lower than the prevalence of nini-hood reported in Figure 1 (range $=0.28$ to 0.58 ), which means that family circumstances are positively associated with nini-hood in almost all countries, net of socioeconomic conditions.

The associations in Figure 2 display remarkably consistent direction across countries, although they differ in size. For instance, living in a nuclear-own household is positively associated with the proportion of 'nini' women, with coefficients that range from 0.07 to 0.54 , implying ninihood gaps of up to a relative risk of 1.72 compared to women living in nuclear households (left panel). As expected, this association is negative for men in all countries except in Brazil (coefficient $=0.01$, right panel). Likewise, the coefficients for "Single-parent-own" households are all positive (except for Paraguay) among women, while they display inconsistent patterns for men (range $=-0.25$ to 1.62 ). These patterns are potentially due to the very small share of men living as single fathers (see Table A1 in the Appendix). All other household types display heterogeneous relationships with the prevalence of nini-hood among men and women.

Next, gender differences are apparent in terms of parenthood and partnership status. Regardless of the timing of the transition to childbearing (teenage vs. young adulthood), in all 12 countries, motherhood is positively associated with nini-hood. The absolute values of these coefficients are comparable to, and for some countries larger than, those of the household head's educational attainment (variable Education hh). The similarity in the magnitude of these coefficients implies hat parenthood and social origin-proxied by the household head's education level - have equally strong and significant associations with nini-hood. Likewise, compared to women without partners, those married or cohabiting at the census time are more 
likely to be ninis. The coefficients for both married individuals and cohabitors are similar, and in some countries are greater than 0.5 , which implies nini-hood gaps above the relative risk of 1.65 (e.g., Mexico, Ecuador, Peru, Costa Rica, and Panama). For men, however, parenthood and partnership status tend to show a negative correlation with nini-hood.

As for the control variables, age displays relatively small coefficients, rural areas seem more affected by nini-hood (particularly among women) and the largest socioeconomic disparities are associated with the educational attainment of the household head and less with ownership status. The magnitude of the coefficients for the control variables helps us understand better the phenomenon of nini-hood during young adult ages. The coefficients for age indicate that there is not much variation in the prevalence of nini-hood across age groups, i.e., work and school disengagement affect 20 as much as 25 years old. In almost all countries, living in rural areas is associated with a greater proportion of nini-hood. Exceptions to this finding include Honduras, Nicaragua, Paraguay, and Ecuador (only for men). Finally, the two variables related to social origin, particularly the household head's educational attainment, indicate that ninihood is more prevalent among socioeconomically disadvantaged households, i.e., those where the household head does not own the dwelling and those where the household head completed primary education at most.

Figure 3 displays predicted proportions of individuals in the 'Not at school/in work (nini)' group for selected explanatory categories of the family-related variables by educational attainment of the household head, which allows us to cast light on heterogeneity by social origin. This figure shows that social origin matters more for nini-hood among women than men. According to these predicted proportions, the relatively few nini men are a mix of low and high social class origin individuals. In contrast, the majority of nini women come from households where the household head completed, at most, primary education, i.e., low social origin. The distributions of the proportions pertaining to the lowest ("less than primary") and the highest 
("secondary education or more") social classes differ among women but largely overlap among men. The almost non-overlapping distributions of the proportions by social class origin among women and the entire overlapping distribution of proportions among men speak to the structural nature of the influences of gender and social class origin on youth education and employment opportunities.

Finally, the erratic pattern of the predicted proportions for men in "Single-parent-own" households is likely due to the small number of men in this category, which underlines the gendered nature of household composition. Whereas a sizable proportion of women live with their children (and no partner, potentially due to separation, divorce, or the informality of union), few men are single parents. The combination of single parenthood and low social origin exacerbates women's likelihood of being 'nini.'

Figures 1 to 3 indicate that disengagement from formal education and work affects primarily socially disadvantaged women. Likely, these women are engaged in reproductive and economically productive (yet informal) activities. Their contributions to the national economies and the reproduction of the population are not accounted for nor recognized, and the early detachment from formal institutions such as pension fund suggests they may suffer from economic deprivation later in their lives.

Formal Work: A Male and Socially Advantaged Realm

Figure 4 shows the country-specific coefficients from models predicting the proportion of women (left panel) and men (right panel) who declared having a formal job at the census moment. In contrast to the proportions of 'nini,' results for the proportion 'In work' suggest that labor force participation is more prevalent among non-nuclear households for both women and men, positively associated with partnership formation and parenthood for men, and it displays a positive slope over age for both genders. 
$* * *$ Figure 4 here $* * *$

Almost all coefficients for non-nuclear households are positive, showing that young adults living in these households are more likely to be formally working than young individuals living exclusively with their parents and siblings. Together with the results presented in Figure 2, these coefficients are indicative of a potential protective role of nuclear families. Young adults in nuclear configurations are more likely to be attending school, which, for degree and labor credentials accumulation, is a desirable condition for people within our age range of focus (see figure $\mathrm{A} 1$ in the Appendix).

Gender differences in the coefficients for parenthood and partnership align with our interpretation of the formal labor market as a male realm. Regardless of the timing, having children and forming a union (cohabiting or marriage) are associated with a higher proportion of working young men. These associations are mostly negative for women, and the coefficients display more considerable heterogeneity than those for men.

Finally, engagement in the labor force is positively associated with age. Due to lower labor force participation among women compared to men, the absolute age gaps in the proportion of individuals 'In work' are comparable between men and women, and sometimes even greater among the former. In addition, there are significant differences in labor force engagement among men by social class origin. Young men living in households where the head has some secondary or higher education are less likely to be working (and more likely to be studying, see Figure A1), whereas young men in lower class households are more likely to be working. These disparities among social classes are weak or non-existent for young women.

Despite the absence of overall social origin differences in the likelihood of working for women (Figure 4), Figure 5 uncovers the differences in the relationship between family and work by 
social class. According to figure 5, which shows the predicted proportion of individuals 'In work", these differences by social class origin apply to both men and women.

$$
* * * \text { Figure } 5 \text { here } * * *
$$

First, the social class gradient in the proportion 'In work' is more apparent among men than women across household types. For men, except in Brazil and Panama, whenever the household head attended secondary education, young adults were less likely to be working at the time of the census across all household types. For women, the distributions of the predicted proportions for the highest and the lowest social origin groups overlap, except among 'Singleparent' and 'Other' household types. Second, the social class gradient in the predicted proportion of working individuals across the parenthood categories is similar for men and women. Third, the class gradient in the proportion working by partnership status is weak among women and very apparent among men, which further confirms the gendered aspect of the transition to adulthood in LAC and distinguishes partnership dynamics from parenthood.

\section{Limited Intergenerational Mobility for Young Mothers}

Among those in the formal labor market, upward intergenerational mobility is a highly desirable outcome, for a region with limited social mobility such as LAC. In Figure 6 and Figure 7, we show the results of models predicting upward mobility, coded as 1 if the individual occupies a higher ranked occupation compared to their parents, and 0 otherwise. This analysis is based on the sub-sample of individuals who at the time of the census co-resided with at least one of their parents (around 53 percent of our original sample, see Table 1, columns 2 and 3). Table A2 in the appendix shows the differences in the characteristics of young adults depending on whether they live with their parents. At the end of this section, we comment on how this sample selection affects our results of mobility analysis and our conclusions. 
Table A2 shows that men are more likely to co-reside with parents than women (59 vs. 47 percent, respectively). Among those living with their parents, 67 percent of men and 50 percent of women work. This is the sub-sample for which we are able to compare young adults' occupational status with that of the highest achiever coresident parent. Descriptive statistics shown in Table A2 provide evidence that women are more likely to be upwardly mobile than men (47 vs. 29 percent, respectively).

Figure 6 shows that, among all individuals who work and co-reside with parents, upward mobility does not display a clear pattern among those who live with only one or both parents. In general, the coefficients are small (except for the 'Other' category, potentially due to sample size, refer to Table A1) and they are both positive and negative. The only exception are coefficients for men in 'Single-parent' households, which are mostly headed by women, meaning that upward mobility is probably associated with the lower occupational rank of the single mothers.

$* * *$ Figure 6 here $* * *$

Parenthood, particularly teenage parenthood, is associated with lower upward mobility among women in all countries, whereas the associations vary for men. Because women display higher upward mobility than men (see Table A2), the consistently negative associations between parenthood and upward mobility imply larger differences in the proportion upwardly mobile by parenthood status among women compared to men. This result adds up to our argument about the gendered nature of labor force participation and extends it to the realm of intergenerational occupational mobility. Not only are women less likely to work in the formal sector (and more likely to become nini) if they have children, but when working, they are also less likely to be upwardly mobile compared to their childless counterparts. The coefficients for the categories of partnership instead, do not display major gender differences. Both men and 
women in cohabiting unions display lower propensity to be upwardly mobile than their married counterparts.

Upward mobility increases across age groups and is less prevalent in rural compared to urban areas. Households where the household head did not finish primary school and household where the household head acquired secondary education or more, are associated with lower upward mobility compared to households where the household head completed primary education.

The lack of difference in upward intergenerational mobility between individuals with the lowest and highest social class origin (proxied by the household head educational attainment) could be related to the sample selection. This selectivity implies that for young adults from high social class origin, upward mobility by age 20-25 is rather an uncommon outcome because the expected path is to further educational attainment (see Figures A1 and A2 in the Appendix), under the context of delaying transition to adulthood. Instead, for individual from low social classes, early labor force engagement may channel them to occupations of lower or equal rank compared to those of their parents. Finally, among middle social class individuals (i.e., those residing in households where the household head finished primary school), delayed departure from parental home may be associated with higher propensity to finish school, acquire vocational training and work in slightly better ranked occupations compared to their parents. Indeed, our additional analysis (not shown) suggests that most of the occupational mobility we observed happens between adjacent occupations. These results mean that the higher proportion of upwardly mobile young individuals among middle class households is driven by the fact that their parents are in occupations at the lower end of the occupational rank (e.g., 'Plant and machine operators and assemblers'). 
These class-specific implications of our sample, along with the absence of gender differences in the association between family circumstances and upward intergenerational mobility are consistent with the predicted proportion of upwardly mobile individuals by educational attainment of the household head (Figure 7). According to Figure 7, upward intergenerational mobility is relatively rare among young adults from high social class backgrounds (i.e., household where the head acquired secondary education or more). Instead, in most countries, young adults from middle class background are the most upwardly mobile. This conclusion glosses over some country- and variable-specific patterns, however, and given the limitations of our data; it seems a plausible overarching interpretation. Country-specific analyses with proper retrospective information are needed to test if these patterns are valid when observed among all individuals (i.e., those who co-reside with parents, and those who do not), and perhaps at a later stage in life (after age 25).

$$
* * * \text { Figure } 7 \text { here } * * *
$$

Taken together, result for institutional disengagement and upward intergenerational occupational mobility suggest that the interlinks among transition to adulthood markerspartnership formation, parenthood, and entrance (exclusion from) the labor market-are gendered and socially stratified. Despite the cross-national diversity, gender and class difference are pervasive. The next section discusses the implications of these patterns for LAC, and more broadly for research on inequality in opportunities and demographic trends.

\section{Discussion}

Understanding gender inequality in labor market engagement and intergenerational mobility is essential to social progress in Latin America. For young adults, delayed entrance into work force is potentially positive if in lieu of work they accumulate human capital through education. 
However, the number of individuals who are neither working nor studying, commonly known as nini, is alarmingly high in Latin America.

The nini phenomenon hinders the region's full potential for economic growth at a time of having a relatively large working force population in comparison to its old and young, often considered a window of advantageous dependency ratio which can lead to the reaping of the demographic dividend (Saad, 2011). The failure to harness the productivity of the youth often culminates to social insecurity and unrest. Along with other factors that contributed to fractured societies, these inequalities manifested in massive demonstrations in several LAC countries in the recent years (Busso \& Messina, 2020).

One of the key issues that hinder educational and occupational engagement of young adults stems from early family formation, especially for women. We stress that most young women simply defined as nini here are not necessarily idle. Rather, they are likely to be performing unpaid care work and household chores, and/or working in the informal economy. Excluding this population from the nini universe, as some studies suggest, in our view would artificially diminish the severity of gender inequality in the labor market.

In our study, we identified clear gender and social class gradients on the relationship between early partnership and parenthood, and human capital accumulation for young adults in Latin America. We considered a wide range of household and socioeconomic variables such as living with dual or single parent(s), extended or composite households, urban or rural residence, home ownership, and the education level of the household head for young adults in 12 Latin American countries using the IPUMS-I census microdata. Consistent with findings from prior studies, we found that women have a far higher tendency to be a nini, especially in Central America. Being in a partnership has a positive association for women and a negative association for men with being a nini, supporting the pervasiveness of a male breadwinner 
model in conjugal households. Family educational level, a proxy for social class, acts as a protective barrier against the risk of becoming a nini, particularly for women.

For those who are engaged in the labor market, intergenerational mobility is more apparent for men than for women who are partnered and had children at young ages, suggesting that early family formation might entail lost opportunities to accrue human capital in the form of schooling or early work experience during the transition to adulthood. It is important to note that roughly half of young adults in the study coreside with their parents. Despite the relative norm of a later departure from parental home in LAC compared to other parts of the world, those who live with their parents at the ages of 20-25 are still hold some observable and perhaps unobservable characteristics to those who do not. Due to a large sample size, we can control for many of those characteristics and infer intergenerational mobility of occupation through intergenerational coresidence, despite the limitations.

Given the size of the informal economy in LAC countries (ILO, 2013; Villanueva \& Lin, 2020), and due to the data collection methodologies, which prevent us from identifying informal workers, the working circumstances of individuals in the "not in school nor in work (nini)' category should not be read as mere inactivity. Previous research has shown the heterogeneity in the activities of this group (Santillan Pizarro \& Pereyra, 2020). Survey that focuses on detailed time-use, such as Encuesta sobre Trabajo No Remunerado y Uso del Tiempo (ETNRyUT) of Argentina, facilitates the understanding of invisible work done by those that can only be broadly defined as nini using other data sources, such as the census. Besides being inactive in the formal work (i.e., not engaged in any visible economic activity, including job search), men and women in this category may be working in the informal sector, engaged in unstable/temporary jobs, taking care of children or older generations, or permanently disabled (Assusa, 2019; Villanueva \& Lin, 2020). However, to our knowledge, no data exist to comprehensively illuminate the relationship between early family formation, human capital 
engagement that is inclusive of informal work, and intergenerational mobility across a large number of LAC countries.

Our work identifies the association between early family formation and exclusion from the formal social sphere, and as a result, inaccessibility to social safety nets such as unemployment insurance, health care systems and pension schemes. The transition to adulthood for a nini, or who appears to be a nini, is marked by disadvantages vis-a-vis those working or studying formally. Our findings support the concept that invisibility leads to vulnerability, especially in the context of single and young parenthood. Therefore, we argue that the lack of emphasis on the heterogeneity of the nini group does not lessen its relevance and its relationship to social disadvantage.

Furthermore, this study highlights the importance of adjusting the gendered lens in viewing women's engagement with public life from a global south perspective, which may significantly deviates from the narratives mainly conceptualized from northern perspectives (Chant, 1997). We argue that in the Latin American scenario of high prevalence of single motherhood under regimes of limited social protection (ECLAC, 2020), women's engagement in the formal labor market becomes a vital predictor for the economic security of themselves and of their offspring. Extended periods of formal labor market absence expose female-headed families to a lifetime of vulnerability. 


\section{References}

Amarante, V., Colacce, M., \& Manzi, P. (2017). The gender gap in pensions in Latin America. International Social Security Review, 70(2), 57-85. https://doi.org/10.1111/issr.12135

Amarante, V., \& Rossel, C. (2018). Unfolding Patterns of Unpaid Household Work in Latin America. Feminist Economics, 24(1), 1-34. https://doi.org/10.1080/13545701.2017.1344776

Angel-Urdinola, D. F., \& Wodon, Q. (2006). The Gender Wage Gap and Poverty in Colombia. LABOUR, 20(4), 721-739. https:/doi.org/10.1111/j.1467-9914.2006.00358.x

Aragao, C., \& Villanueva, A. (2021). How do mothers work? Kin coresidence and mothers' work in Latin America. Demographic Research, 45(30), 917-956.

https://doi.org/10.4054/DemRes.2021.45.30

Assusa, G. (2019). Ni jóvenes, ni desempleados, ni peligrosos, ni novedosos. Una crítica sociológica del concepto de "jóvenes nini” en torno los casos de España, México y Argentina. Cuadernos de Relaciones Laborales, 37(1),91-111. https://doi.org/10.5209/CRLA.63821

Azevedo, V. M. R., \& Bouillon, C. P. (2010). Intergenerational Social Mobility in Latin America: A Review of Existing Evidence. Revista de Análisis Económico-Economic Analysis Review, 25(2), 7-42.

Becker, G. S. (1993). A Treatise on the Family. https://www.hup.harvard.edu/catalog.php?isbn=9780674906990

Behrman, J. R., Gaviria, A., Székely, M., Birdsall, N., \& Galiani, S. (2001). Intergenerational Mobility in Latin America. Economía, 2(1), 1-44.

Ben Yahmed, S. (2018). Formal but Less Equal. Gender Wage Gaps in Formal and Informal Jobs in Urban Brazil. World Development, 101, 73-87. https://doi.org/10.1016/j.worlddev.2017.08.012

Blanden, J. (2009). How Much Can We Learn from International Comparisons of Intergenerational Mobility? In CEE Discussion Papers (No. 0111; CEE Discussion Papers). Centre for the Economics of Education, LSE. https://ideas.repec.org/p/cep/ceedps/0111.html 
Busso, M., \& Fonseca, D. R. (2015). Female Labor Force Participation in Latin America: Patterns and Explanations (Working Paper No. 187). Documento de Trabajo. https://www.econstor.eu/handle/10419/127703

Busso, M., \& Messina, J. (Eds.). (2020). The Inequality Crisis: Latin America and the Caribbean at the Crossroads. Inter-American Development Bank. https $/ /$ doi.org/10.18235/0002629

Caffe, S., Plesons, M., Camacho, A. V., Brumana, L., Abdool, S. N., Huaynoca, S., Mayall, K., Menard-Freeman, L., de Francisco Serpa, L. A., Gomez Ponce de Leon, R., \& ChandraMouli, V. (2017). Looking back and moving forward: Can we accelerate progress on adolescent pregnancy in the Americas? Reproductive Health, 14(1), 83. https://doi.org/10.1186/s 12978-017-0345-y

Camou, M., \& Maubrigades, S. (2017). The lingering face of gender inequality in Latin America. In Has Latin American Inequality Changed Direction? (pp. 219-241). Springer.

Canudas-Romo, V., \& Aburto, J. M. (2019). Youth lost to homicides: Disparities in survival in Latin America and the Caribbean. BMJ Global Health. https://gh.bmj.com/content/4/2/e001275.abstract

Casanova, E. M. de. (2019). Dust and dignity: Domestic employment in contemporary Ecuador. ILR Press, an imprint of Cornell University Press.

CEPAL. (2019). Panorama Social de América Latina 2018. CEPAL. https://www.cepal.org/es/publicaciones/44395-panorama-social-america-latina-2018

Chanel, E., \& Garcia Castro, M. (1989). Muchachas No More: Household Workers in Latin America and the Caribbean (1st ed.). Temple University Press.

Chant, S. (1997). Women-Headed Households: Diversity and Dynamics in the Developing World. Springer.

Chioda, L. (2011). Work and family: Latin America and Caribbean women in search of a new balance. The World Bank. https://openknowledge.worldbank.org/bitstream/handle/10986/12489/686320ESW0P11500G enderRSOfullreport.pdf?sequence $=1 \&$ is Allowed=y 
Conde-Agudelo, A., Belizán, J. M., \& Lammers, C. (2005). Maternal-perinatal morbidity and mortality associated with adolescent pregnancy in Latin America: Cross-sectional study. American Journal of Obstetrics and Gynecology, 192(2), 342-349. https://doi.org/10.1016/j.ajog.2004.10.593

De Hoyos, R., \& Gutiérrez Fierros, C. (2017). Ninis en México: Atrapados entre la guerra contra el narcotráfico y la crisis económica. Vida En Movimiento: Problemas y Políticas Públicas, 3765.

De Hoyos, R., Popova, A., \& Rogers, H. (2016). Out of School and Out of Work: A Diagnostic of Ninis in Latin America (Working Paper No. 7548). World Bank. https://openknowledge.worldbank.org/handle/10986/23723

Deere, C. D., \& Leon, M. (2003). The Gender Asset Gap: Land in Latin America. World Development, 31(6), 925-947. https://doi.org/10.1016/S0305-750X(03)00046-9

Dobson, A. J., \& Barnett, A. G. (2008). An Introduction to Generalized Linear Models, Third Edition (3rd edition). Chapman and Hall/CRC.

Dongarwar, D., \& Salihu, H. M. (2019). Influence of Sexual and Reproductive Health Literacy on Single and Recurrent Adolescent Pregnancy in Latin America. Journal of Pediatric and Adolescent Gynecology, 32(5), 506-513. https:/doi.org/10.1016/j.jpag.2019.06.003

ECLAC. (2020). Social protection forfamilies with children and adolescents in Latin America and the Caribbean: An imperative to address the impact of COVID-19 (p. 21). https://repositorio.cepal.org/bitstream/handle/11362/46490/1/S2000744_en.pdf

Esteve, A., \& Florez-Paredes, E. (2018). The Stability Paradox: Why Expansion of Women's Education Has Not Delayed Early Union Formation or Childbearing in Latin America. Studies in Family Planning, 49(2), 127-142. https://doi.org/10.1111/sifp. 12055

Esteve, A., García-Román, J., \& Lesthaeghe, R. (2012). The family context of cohabitation and single motherhood in Latin America. Population and Development Review, 38(4), 707-727.

Esteve, A., Lesthaeghe, R., \& López-Gay, A. (2012). The Latin American Cohabitation Boom, 19702007. Population and Development Review,38(1), 55-81. https://doi.org/10.1111/j.17284457.2012.00472.x 
Galambos, N. L., \& Martínez, M. L. (2007). Poised for Emerging Adulthood in Latin America: A Pleasure for the Privileged. Child Development Perspectives, 1(2), 109-114. https://doi.org/10.1111/j.1750-8606.2007.00024.x

Gangl, M., \& Ziefle, A. (2009). Motherhood, labor force behavior, and women's careers: An empirical assessment of the wage penalty for motherhood in britain, germany, and the united states. Demography, 46(2), 341-369. https://doi.org/10.1353/dem.0.0056

Ganzeboom, H. B. G., \& Treiman, D. J. (1996). Internationally Comparable Measures of Occupational Status for the 1988 International Standard Classification of Occupations. Social Science Research, 25(3), 201-239. https://doi.org/10.1006/ssre.1996.0010

Gasparini, L., Marchionni, M., Badaracco, N., \& Serrano, J. (2015). Characterizing Female Participation Changes. In Bridging gender gaps? The rise and deceleration offemale labor force participation in Latin America (pp. 151-173).

Gindling, T. H., \& Oviedo, L. (2008). Female-headed single-parent households and poverty in Costa Rica (No. 94; CEPAL Review).

Gong, X., \& van Soest, A. (2002). Wage differentials and mobility in the urban labour market: A panel data analysis for Mexico-ScienceDirect. Labour Economics, 9(4), 513-529.

Gough, I. (2010). Welfare regimes in development contexts: A global and regional analysis. In Insecurity and Welfare Regimes in Asia, Africa and Latin America: Social Policy in Development Contexts (pp. 15-48). Cambridge University Press. https://www.cambridge.org/core/books/insecurity-and-welfare-regimes-in-asia-africa-andlatin-america/CD7C905DE6D465078BF8210B10C2DD45

ILO. (2013). Trabajo decente e igualdad de género. Políticas para mejorar el acceso y la calidad del empleo en América Latina y el Caribe. http://www.ilo.org/santiago/publicaciones/WCMS_233161/lang--es/index.htm Juárez, F., \& Gayet, C. (2014). Transitions to Adulthood in Developing Countries. Annual Review of Sociology, 40(1), 521-538. https://doi.org/10.1146/annurev-soc-052914-085540 
Klasen, S. (2019). What Explains Uneven Female Labor Force Participation Levels and Trends in Developing Countries? The World Bank Research Observer, 34(2), 161-197. https://doi.org/10.1093/wbro/lkz005

Leyva, G., \& Negrete, R. (2014). NiNi: Un término ni pertinente ni útil. Coyuntura Demográfica, 5.

Liu, C., Esteve, A., \& Treviño, R. (2017). Female-Headed Households and Living Conditions in Latin America. World Development, 90(637768), 311-328. https://doi.org/10.1016/j.worlddev.2016.10.008

Miller, A. (2009). The effects of motherhood timing on career path. Journal of Population Economics, $24,1071-1100$.

Minnesota Population Center. (2020). Integrated Public Use Microdata Series, International: Version 7.3. https://doi.org/10.18128/D020.V7.2

Navarrete Lopez, E. L., \& Padron Innamorato, M. (2021). (Re)significando a los jovenes que ni estudian ni trabajan una mirada critica a partir de 14 realidades. El Colegio Mexiquense.

Neal, S., Harvey, C., Chandra-Mouli, V., Caffe, S., \& Camacho, A. V. (2018). Trends in adolescent first births in five countries in Latin America and the Caribbean: Disaggregated data from demographic and health surveys. Reproductive Health, 15(1), 146. https://doi.org/10.1186/s 12978-018-0578-4

Ñopo, H., \& Hoyos, A. (2010). Evolution of Gender Wage Gaps in Latin America at the Turn of the Twentieth Century: An Addendum to "New Century, Old Disparities" (SSRN Scholarly Paper ID 1651711). Social Science Research Network. https $/ /$ papers.ssrn.com/abstract=1651711

Oppenheimer, V. K. (1997). Women's Employment and the Gain to Marriage: The Specialization and Trading Model. Annual Review of Sociology, 23(1), 431-453. https://doi.org/10.1146/annurev.soc.23.1.431

Özcan, B., \& Breen, R. (2012). Marital Instability and Female Labor Supply. Annual Review of Sociology, 38(1), 463-481. https://doi.org/10.1146/annurev-soc-071811-145457

PAHO, (Pan American Health Organization). (2018). The Health of Adolescents and Youth in the Americas (1). 
https://iris.paho.org/bitstream/handle/10665.2/49545/9789275119938_eng.pdf?sequence=17 \&isAllowed $=\mathrm{y}$

Paz, J. (2021). Jóvenes que no estudian y no trabajan en Perú. Un análisis empírico con énfasis en las disparidades por género. In (Re)significando a los jóvenes que ni estudian ni trabajan (pp. 251-288). El Colegio Mexiquense, A.C.

Portes, A., \& Hoffman, K. (2003). Latin American Class Structures: Their Composition and Change during the Neoliberal Era. Latin American Research Review, 38(1), 41-82. https://doi.org/10.1353/lar.2003.0011

Ruggles, S., \& Heggeness, M. (2008). Intergenerational Coresidence in Developing Countries. Population and Development Review, 34(2), 253-281. https://doi.org/10.1111/j.17284457.2008.00219.x

Saad, P. M. (2011). Demographic trends in Latin American and the Caribbean. In D. Cotlear (Ed.), Population aging: Is Latin America ready?

Sánchez-Ancochea, D. (2021). The Costs of Inequality in Latin America: Lessons and Warningsfor the Rest of the World. Bloomsbury Publishing Plc. https://doi.org/10.5040/9781838606275

Santillan Pizarro, M. M., \& Pereyra, E. J. (2020). Juventudes invisibilizadas en Argentina: La relevancia de los trabajos no remunerados y la validez de la categoría nini. Revista Latinoamericana de Población, 14(27), 149-184.

Socolow, S. M. (2015). The Women of Colonial Latin America. Cambridge University Press.

Staab, S. (2012). Maternalism, Male-Breadwinner Bias, and Market Reform: Historical Legacies and Current Reforms in Chilean Social Policy. Social Politics: International Studies in Gender, State \& Society, 19(3), 299-332. https://doi.org/10.1093/sp/jxs010

Torche, F. (2014). Intergenerational Mobility and Inequality: The Latin American Case. Annual Review of Sociology, 40(1), 619-642. https://doi.org/10.1146/annurev-soc-071811-145521

Urdinola, B. P., \& Tovar, J. A. (2019). Time Use and Transfers in the Americas: Producing, Consuming, and Sharing Time Across Generations and Genders. Springer.

Villanueva, A., \& Lin, K.-H. (2020). Motherhood Wage Penalties in Latin America: The Significance of Labor Informality. Social Forces, 99(1), 59-85. https $/ /$ doi.org/10.1093/sf/soz142 
Ward, P. M., Jiménez Huerta, E. R., \& Di Virgilio, M. M. (2015). Housing Policy in Latin American Cities (0 ed.). Routledge. https://doi.org/10.4324/9781315773001 


\section{Tables and Figures}

Table 1. Countries, census year, and sample sizes of all young adults (nini analysis) and subsamples of young adults living with their parents (intergenerational mobility analysis).

\begin{tabular}{|c|c|c|c|c|c|}
\hline \multirow[b]{2}{*}{ Country } & \multirow[b]{2}{*}{ Year } & \multicolumn{3}{|c|}{ Individuals 20 to 25 years old } & \multirow[b]{2}{*}{ Total } \\
\hline & & $\begin{array}{l}\text { No linked to } \\
\text { parents } \\
(1)\end{array}$ & $\begin{array}{c}\text { Linked to parents } \\
\text { unambiguously } \\
\text { (2) }\end{array}$ & $\begin{array}{l}\text { Linked to parents } \\
\text { ambiguously } \\
\text { (3) }\end{array}$ & \\
\hline Brazil & 2010 & $1,035,253$ & $1,126,247$ & 27,043 & $2,188,543$ \\
\hline Costa Rica & 2011 & 19,772 & 29,378 & 648 & 49,798 \\
\hline Dom. Republic & 2010 & 55,984 & 46,726 & 1,985 & 104,695 \\
\hline Ecuador & 2010 & 82,715 & 68,567 & 3,078 & 154,360 \\
\hline El Salvador & 2007 & 26,072 & 30,661 & 1,203 & 57,936 \\
\hline Guatemala & 2002 & 61,259 & 59,789 & 1,051 & 122,099 \\
\hline Honduras & 2001 & 38,670 & 28,993 & 1,161 & 68,824 \\
\hline Mexico & 2010 & 521,516 & 655,221 & 22,678 & $1,199,415$ \\
\hline Nicaragua & 2005 & 32,276 & 30,901 & 1,349 & 64,526 \\
\hline Panama & 2010 & 17,535 & 15,590 & 744 & 33,869 \\
\hline Paraguay & 2002 & 27,627 & 27,316 & 635 & 55,578 \\
\hline Peru & 2007 & 157,849 & 139,749 & 6,728 & 304,326 \\
\hline Total & & $2,076,528$ & $2,259,138$ & 68,303 & $4,403,969$ \\
\hline Percentages & & 47.2 & 51.3 & 1.6 & 100.0 \\
\hline
\end{tabular}

Note: The sample for the nini analysis includes all individuals (i.e., columns 1,2, and 3). The analysis of intergenerational occupational mobility includes only individuals in columns 2 and 3 . 
Figure 1. Employment status and school attendance profiles of 20 to 25 years old individuals in 12 Latin American countries by sex, most recent census sample (2002-2010).

Women

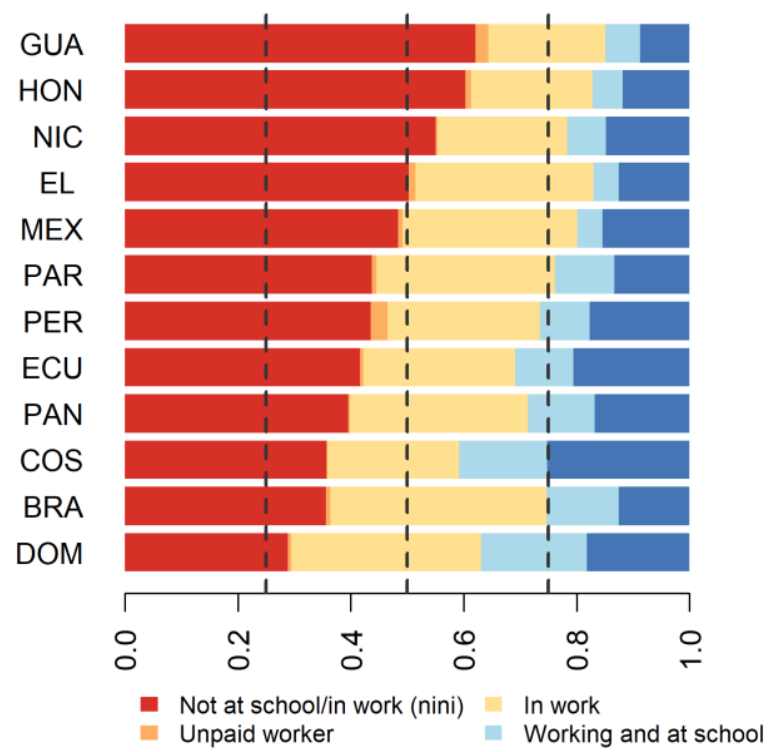

Men

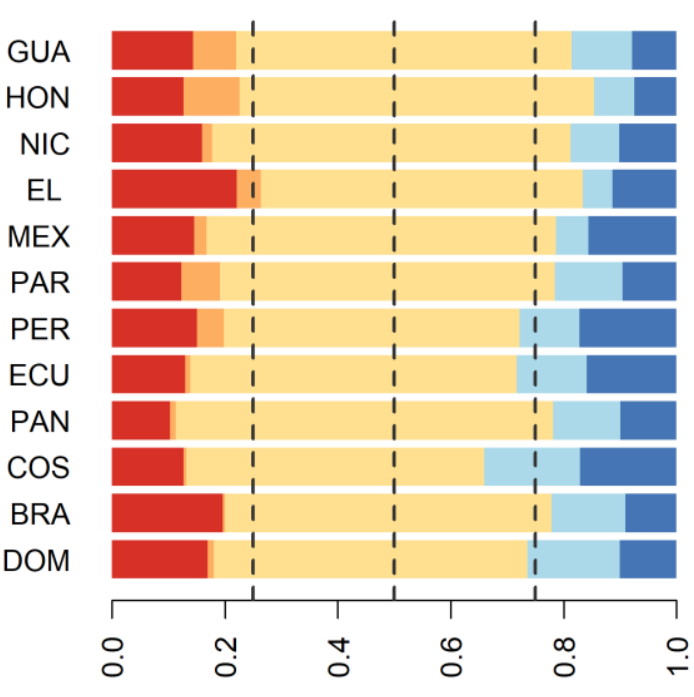

- Attending school 
Figure 2. Country-specific coefficients for models predicting the proportion of individuals in the "Not at school/in work (nini)" category. Light gray markers indicate statistically insignificant differences with respect to the reference category in parenthesis. The intercepts are included next to the country names in the label.

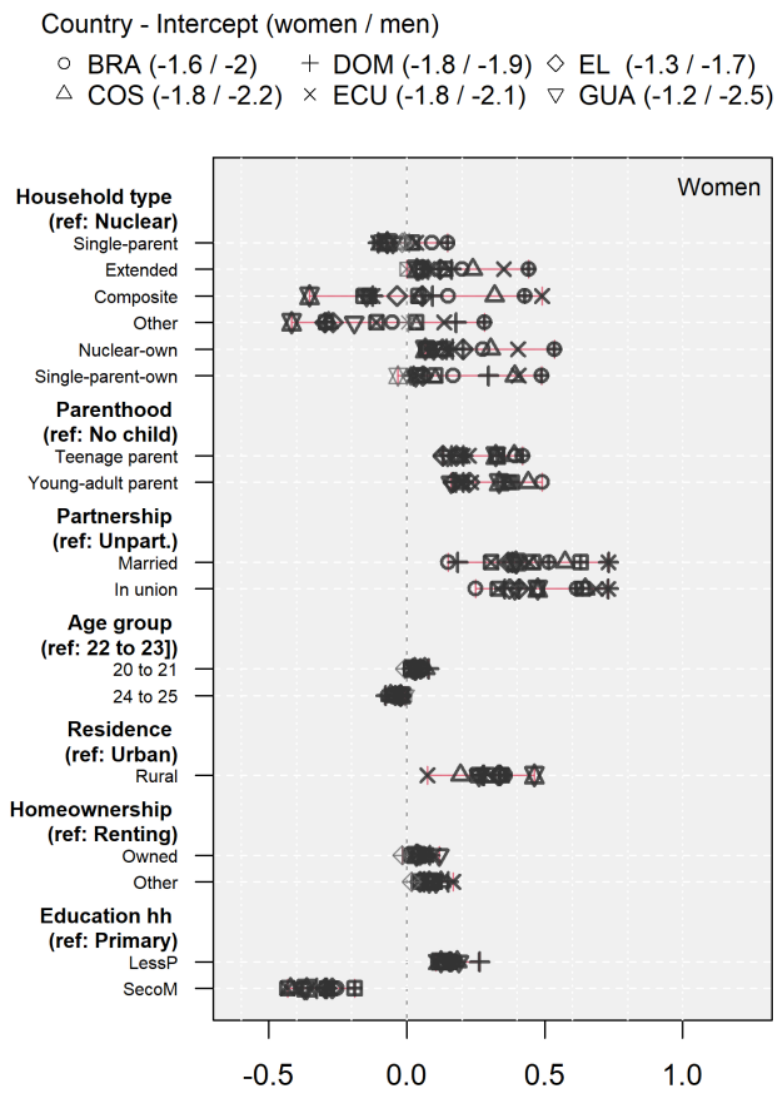

Regression coefficient $\otimes \operatorname{HON}(-1.1 /-2.1) \oplus \operatorname{NIC}(-1.3 /-1.7) \notin \mathrm{PAR}(-1.5 /-2.1)$

* MEX (-1.4/-2) $\rightarrow \operatorname{PAN}(-2 /-2.9) \quad \rightarrow \operatorname{PER}(-1.5 /-2)$

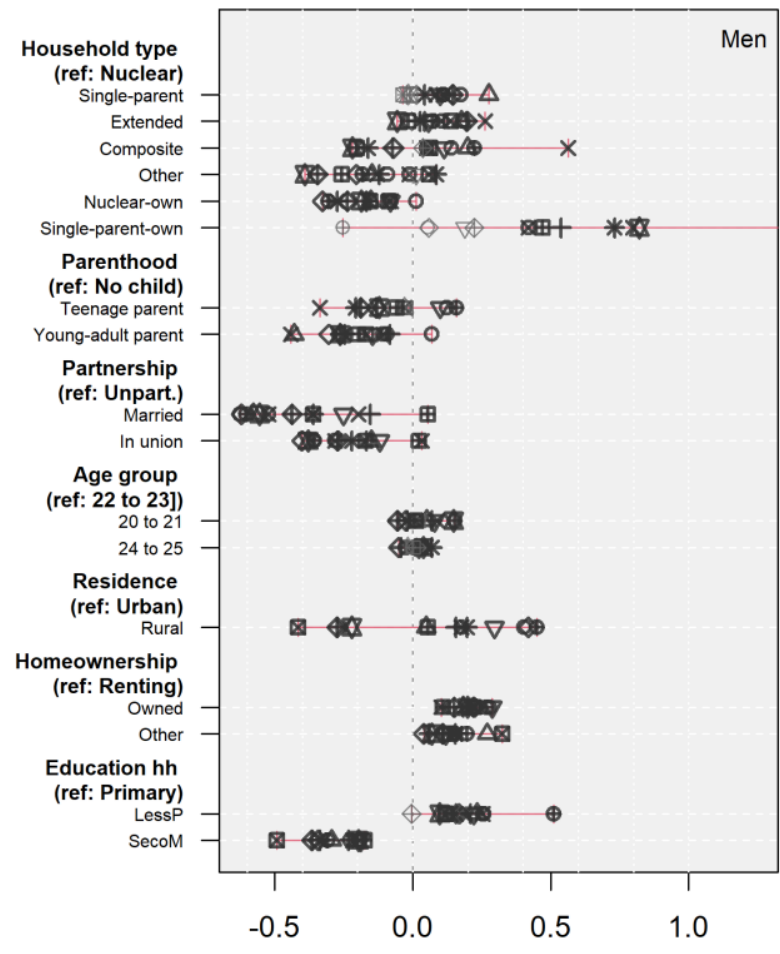

Regression coefficient

Note: We restrict the $\mathrm{x}$-axis to 1.5 to favor visibility. The coefficients that are greater than 1.5 corresponds to Honduras and Costa Rica, where the number of men in 'single-parent-own' households is small, making the estimated coefficient erratic (standard errors $=0.082$ and 0.099 , respectively). 
Figure 3. Predicted proportion of individuals in the 'Not at school/in work (nini)' category by educational attainment of the household head.

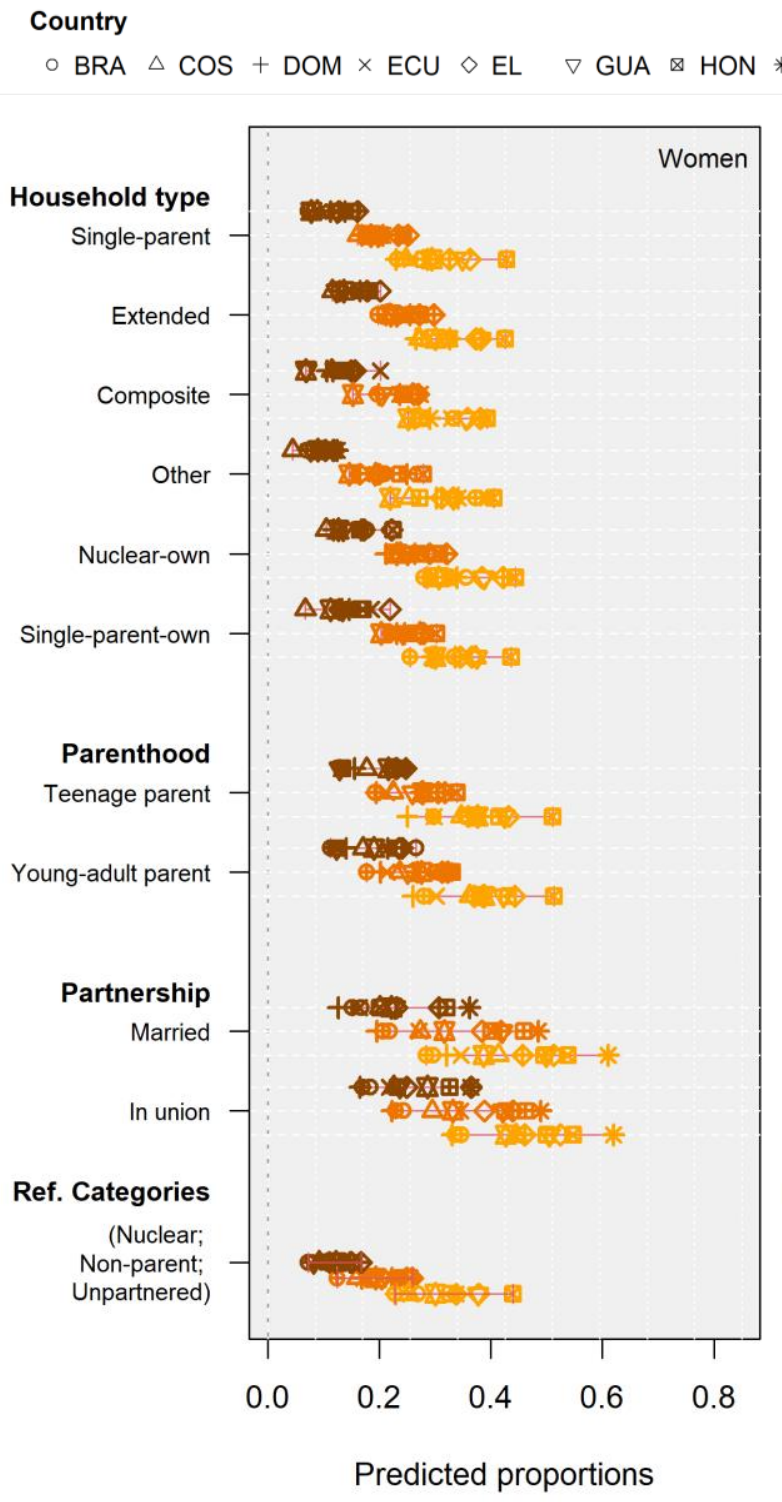

Less than primary
Primary completed

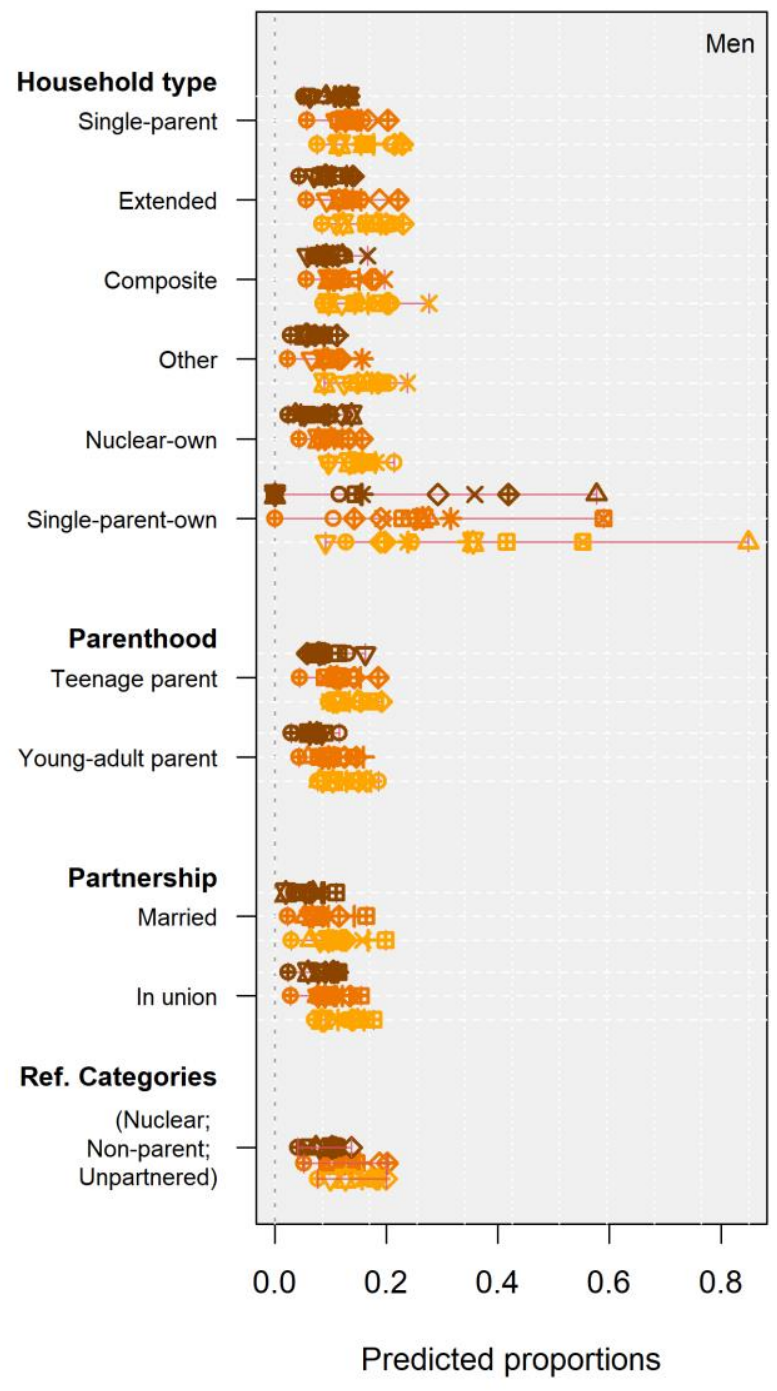

Secondary education or more

Note: Models were fitted separately for three educational attainment levels of the household head: Less than primary, Primary education completed, Some secondary education or more. Proportions are predicted for the reference category of each explanatory variable (Ref. Categories at the bottom). 
Figure 4. Country-specific coefficients for models predicting the proportion of individuals in the "In work" category. Light gray markers indicate statistically insignificant differences with respect to the reference category in parenthesis. The intercepts are included next to the country names in the label.

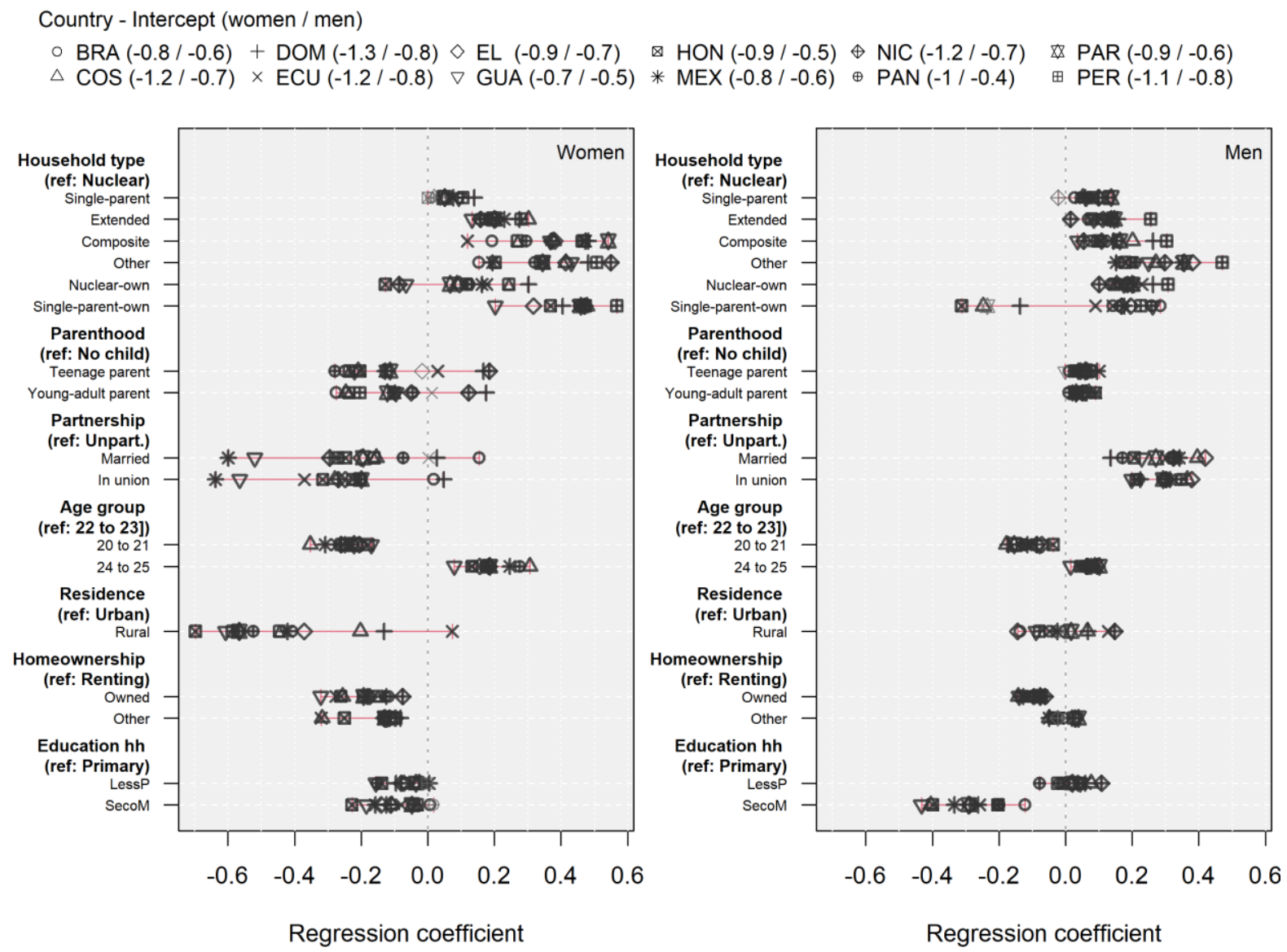

Note: Coefficients range from -.7 to .7; therefore, we find no need to restrict the $\mathrm{x}$-axis as we do in Figure 2. 
Figure 5. Predicted proportion of individuals in the 'In work' category by educational attainment of the household head.

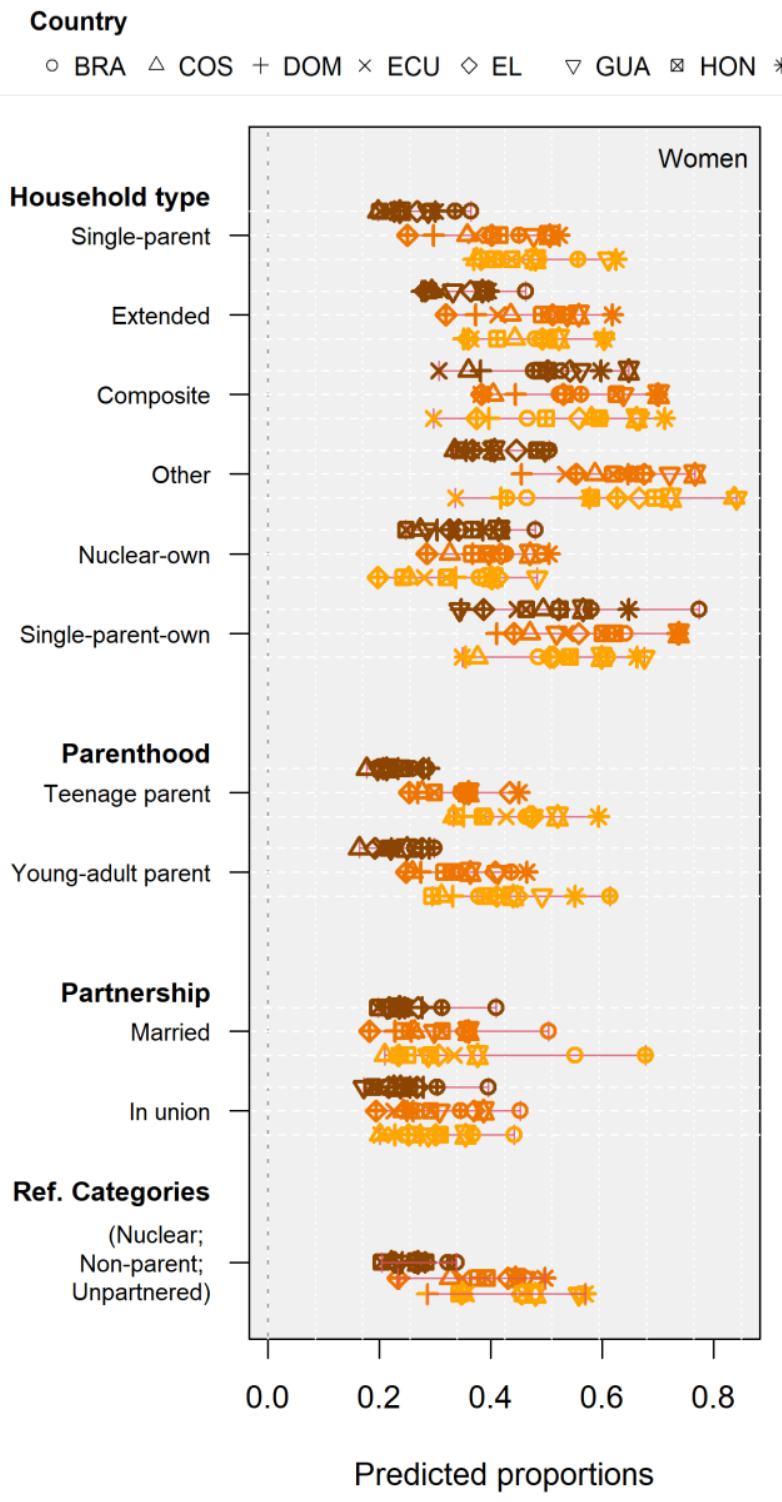

Predicted proportions

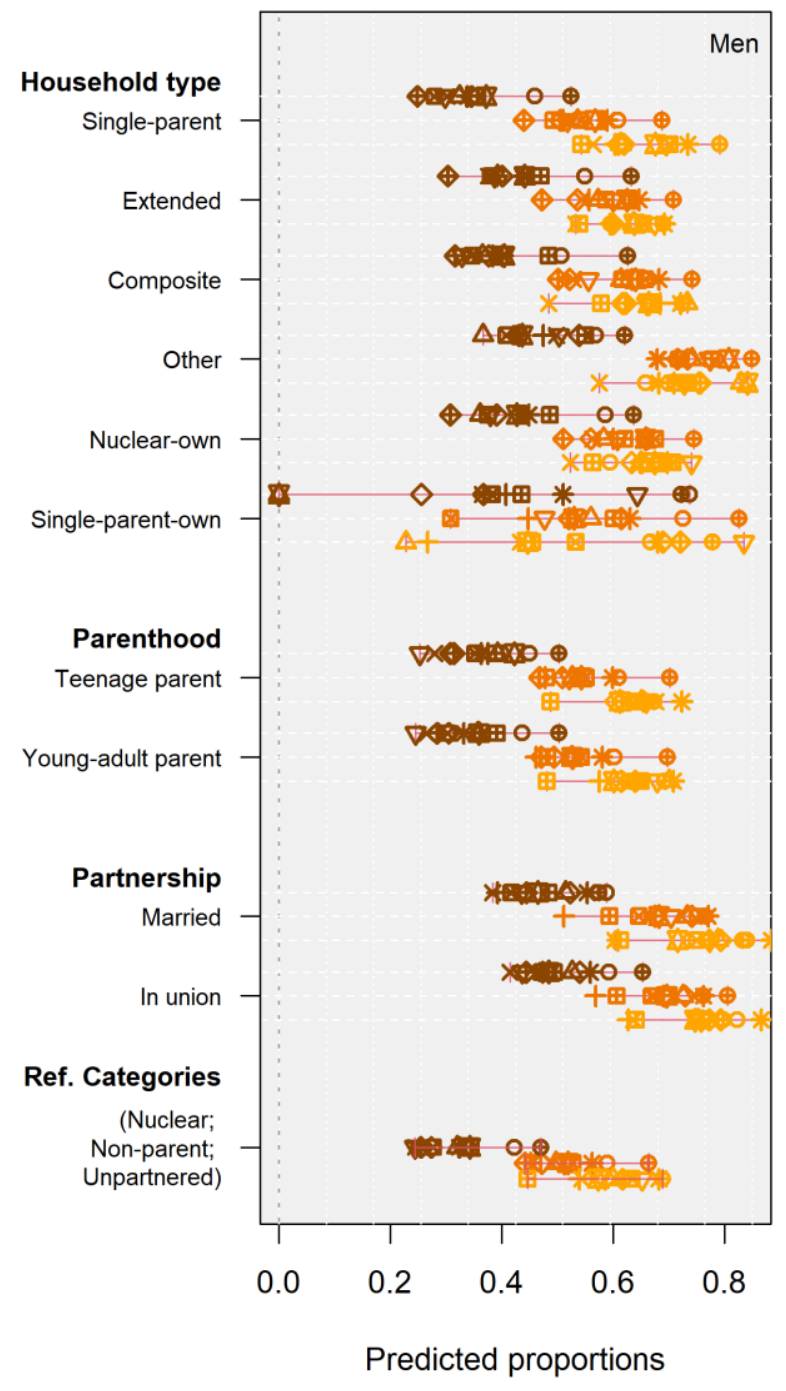

- Secondary education or more

Note: Models were fitted separately for each of the three educational attainment level of the household head: Less than primary, Primary education completed, Some secondary education or more. Proportions are predicted for the reference category of each explanatory variable (Ref. Categories at the bottom). 
Figure 6. Country-specific coefficients for models predicting the proportion of upwardly mobile individuals. Light gray markers indicate statistically insignificant differences with respect to the reference category in parenthesis. The intercepts are included next to the country names in the label.

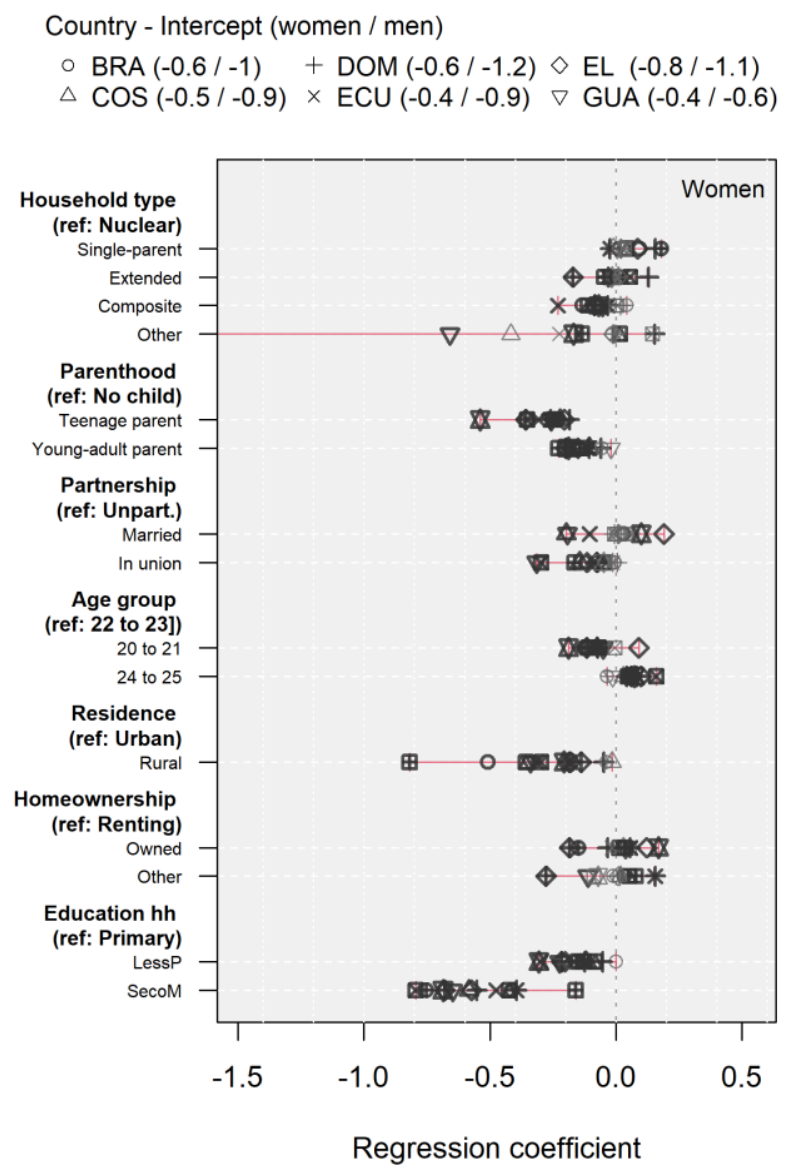

$\begin{array}{lll}\otimes \operatorname{HON}(-0.7 /-1) & \oplus \operatorname{NIC}(-0.3 /-1.4) & \otimes \operatorname{PAR}(-0.5 /-0.8) \\ * \operatorname{MEX}(-0.6 /-1) & \oplus \operatorname{PAN}(-0.3 /-1.1) & \oplus \operatorname{PER}(-0.6 /-1.1)\end{array}$

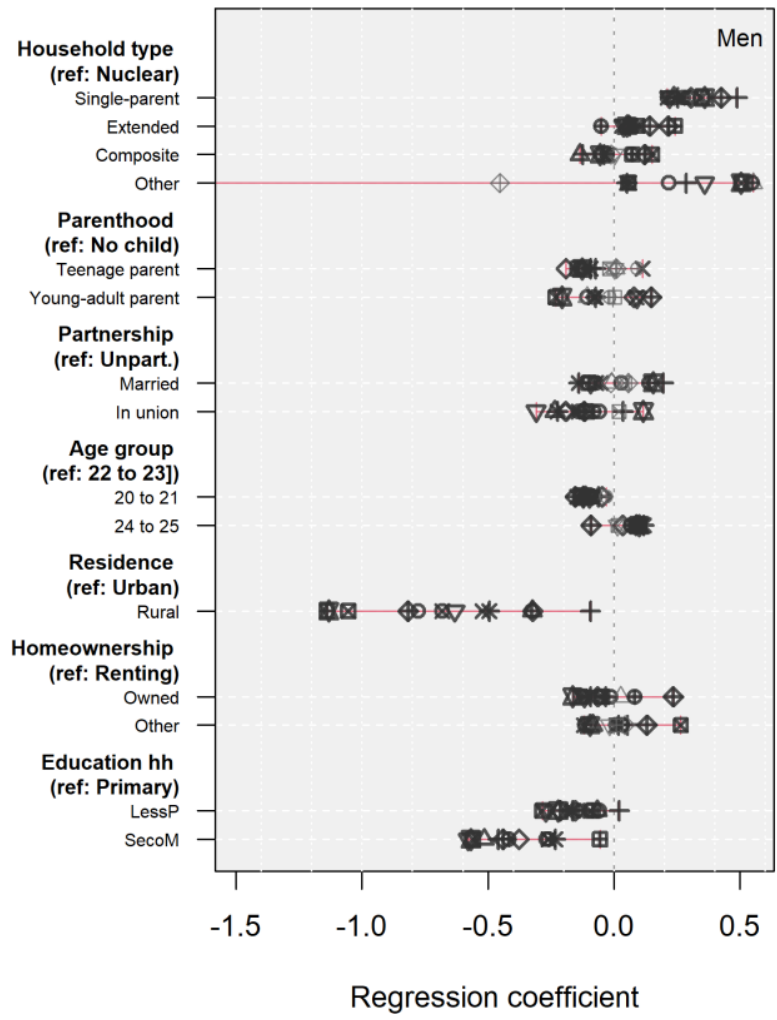

Note: These analyses include only individuals that co-resided with their parents a the time of the census (i.e., columns 2 and 3 in Table 1). Consequently, the variable Household type does not include the 'Single-parent-own' and 'Nuclear-own' categories as these are two categories for young adult who have already left their parental household. 
Figure 7. Predicted proportion upwardly mobile individuals by educational attainment of the household head.

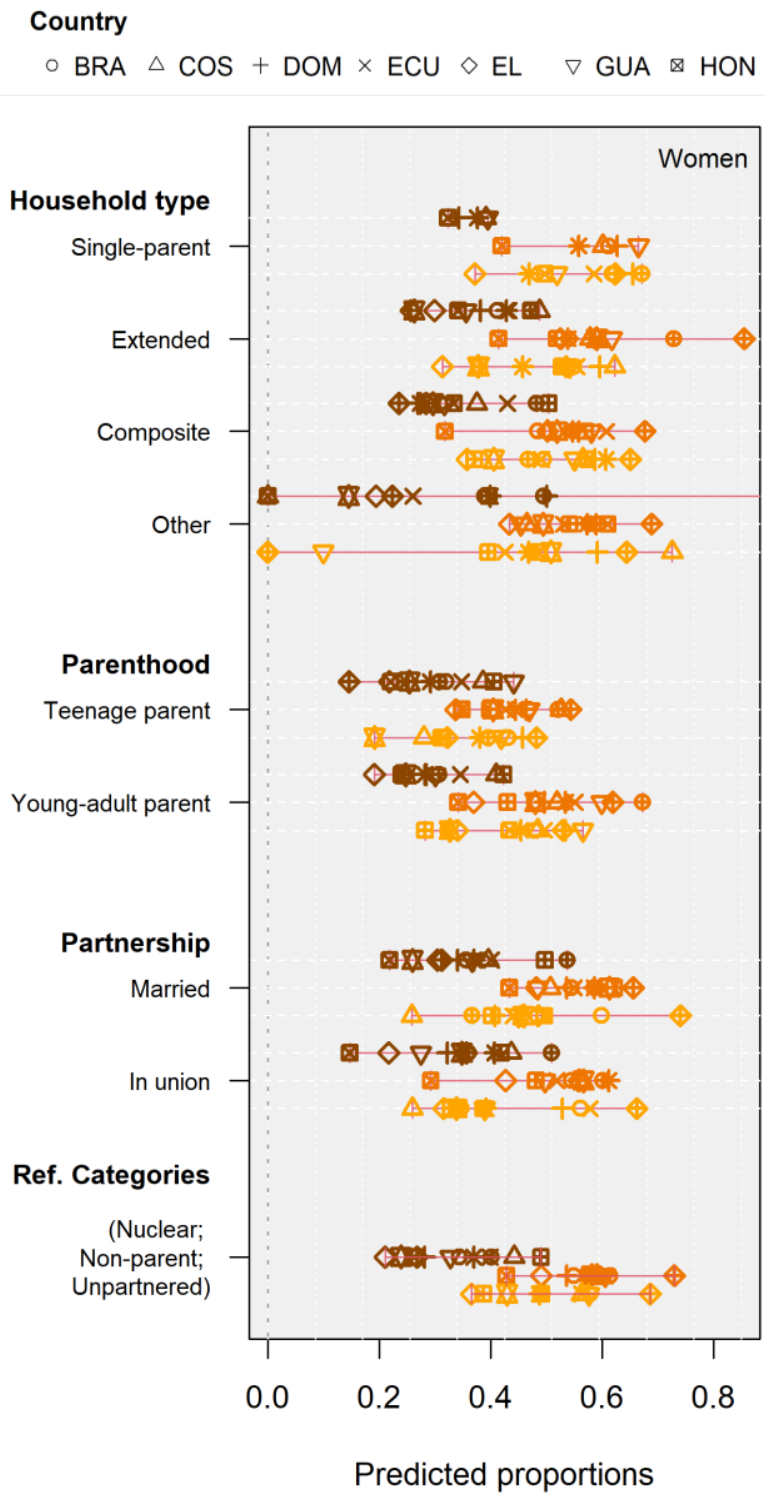

Less than primary
Primary completed

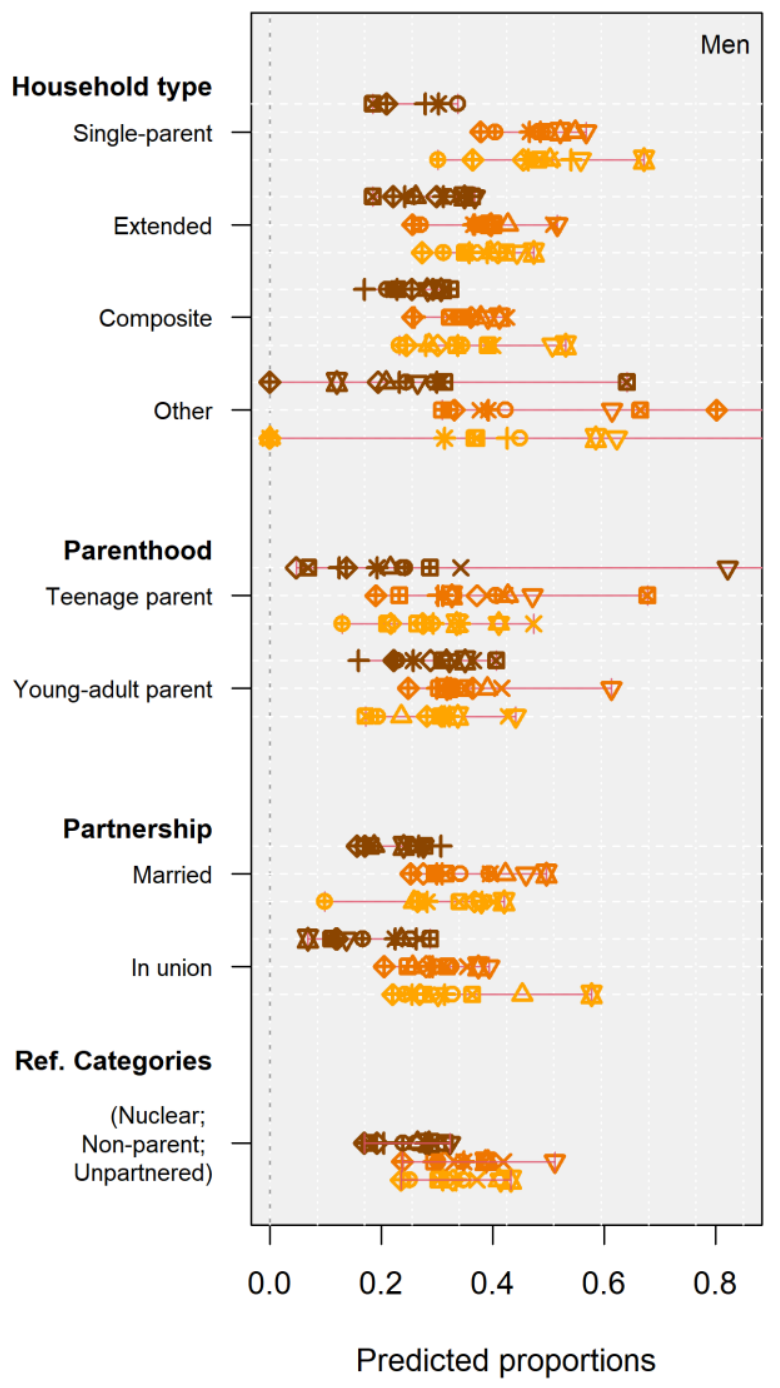

Secondary education or more

Note: Models were fitted separately for each of the three educational attainment level of the household head: Less than primary, Primary education completed, Some secondary education or more. Proportions are predicted for the reference category of each explanatory variable (Ref. Categories at the bottom). 


\section{Appendix}

Table A1. Percentage distribution of explanatory and control variables by country. Most recent census samples from IPUMS-I, 2002-2010

\begin{tabular}{|c|c|c|c|c|c|c|c|c|c|c|c|c|}
\hline \multirow{2}{*}{$\begin{array}{l}\text { Explanatory } \\
\text { variable }\end{array}$} & \multicolumn{12}{|c|}{ Country } \\
\hline & BRA & $\mathrm{COS}$ & DOM & ECU & EL & GUA & $\mathrm{HON}$ & MEX & NIC & PAN & PAR & PER \\
\hline \multicolumn{13}{|l|}{ Household type } \\
\hline Nuclear & 24.7 & 27.8 & 15.3 & 16.4 & 17.8 & 18.3 & 12.7 & 25.1 & 11.5 & 15.5 & 18.2 & 16.5 \\
\hline Single parent & 8.2 & 11.2 & 8.0 & 7.1 & 8.5 & 5.6 & 4.9 & 7.0 & 5.1 & 7.2 & 5.3 & 6.9 \\
\hline Extended & 32.6 & 30.0 & 38.5 & 40.1 & 42.7 & 38.1 & 40.7 & 38.9 & 47.1 & 38.2 & 40.0 & 42.7 \\
\hline Composite & 3.0 & 4.7 & 4.3 & 6.3 & 4.3 & 5.1 & 7.8 & 1.7 & 8.9 & 11.1 & 11.9 & 8.5 \\
\hline Other & 4.6 & 3.5 & 12.9 & 4.1 & 2.4 & 2.2 & 4.8 & 5.4 & 1.6 & 7.2 & 4.6 & 6.3 \\
\hline Nuclear-own & 26.0 & 21.5 & 19.4 & 24.3 & 22.8 & 29.7 & 28.0 & 21.3 & 24.8 & 19.5 & 19.1 & 17.9 \\
\hline \multirow[t]{2}{*}{ Single-parent-own } & 0.8 & 1.2 & 1.8 & 1.8 & 1.6 & 1.0 & 1.1 & 0.6 & 1.0 & 1.3 & 0.8 & 1.2 \\
\hline & 100 & 100 & 100 & 100 & 100 & 100 & 100 & 100 & 100 & 100 & 100 & 100 \\
\hline \multicolumn{13}{|l|}{ Parenthood } \\
\hline Not a parent & 71.9 & 72.2 & 69.5 & 63.2 & 63.5 & 55.8 & 58.0 & 64.5 & 56.5 & 69.7 & 69.5 & 70.2 \\
\hline Teenage parent & 14.5 & 13.8 & 15.6 & 18.8 & 20.0 & 25.0 & 23.3 & 17.4 & 25.1 & 14.9 & 15.3 & 14.0 \\
\hline \multirow[t]{2}{*}{ Young-adult parent } & 13.7 & 14.0 & 14.9 & 18.0 & 16.5 & 19.3 & 18.8 & 18.1 & 18.4 & 15.3 & 15.2 & 15.8 \\
\hline & 100 & 100 & 100 & 100 & 100 & 100 & 100 & 100 & 100 & 100 & 100 & 100 \\
\hline \multicolumn{13}{|l|}{ Partnership } \\
\hline Unpartnered & 63.1 & 67.6 & 62.2 & 55.1 & 60.2 & 48.2 & 50.2 & 58.0 & 49.9 & 57.5 & 65.2 & 61.2 \\
\hline Married & 13.1 & 10.8 & 4.7 & 17.4 & 12.1 & 28.8 & 16.5 & 20.1 & 16.2 & 5.8 & 16.6 & 6.6 \\
\hline \multirow[t]{2}{*}{ In union } & 23.8 & 21.6 & 33.1 & 27.5 & 27.7 & 23.0 & 33.2 & 21.9 & 33.8 & 36.7 & 18.2 & 32.2 \\
\hline & 100 & 100 & 100 & 100 & 100 & 100 & 100 & 100 & 100 & 100 & 100 & 100 \\
\hline \multicolumn{13}{|l|}{ Age group } \\
\hline 22 to 23 & 33.5 & 32.8 & 32.6 & 33.8 & 32.8 & 35.2 & 34.0 & 33.8 & 34.6 & 32.7 & 34.6 & 33.6 \\
\hline 20 to 21 & 33.0 & 34.1 & 35.7 & 33.5 & 34.8 & 34.0 & 35.8 & 34.2 & 33.5 & 34.0 & 36.4 & 33.4 \\
\hline \multirow[t]{2}{*}{24 to 25} & 33.6 & 33.2 & 31.7 & 32.7 & 32.4 & 30.8 & 30.1 & 32.1 & 31.8 & 33.3 & 29.0 & 33.0 \\
\hline & 100 & 100 & 100 & 100 & 100 & 100 & 100 & 100 & 100 & 100 & 100 & 100 \\
\hline \multicolumn{13}{|l|}{ Place of residence } \\
\hline Urban & 85.4 & 73.0 & 75.6 & 65.1 & 63.9 & 50.3 & 51.6 & 78.0 & 56.3 & 68.4 & 62.7 & 78.9 \\
\hline \multirow[t]{2}{*}{ Rural } & 14.6 & 27.0 & 24.4 & 34.9 & 36.1 & 49.7 & 48.4 & 22.0 & 43.7 & 31.6 & 37.3 & 21.1 \\
\hline & 100 & 100 & 100 & 100 & 100 & 100 & 100 & 100 & 100 & 100 & 100 & 100 \\
\hline \multicolumn{13}{|l|}{ Homeownership } \\
\hline Renting & 21.4 & 22.6 & 36.3 & 23.5 & 14.3 & 11.8 & 17.1 & 15.5 & 4.4 & 15.2 & 12.1 & 15.8 \\
\hline Owned & 69.9 & 68.5 & 53.4 & 61.4 & 73.9 & 80.6 & 74.9 & 75.5 & 86.2 & 78.2 & 78.6 & 71.2 \\
\hline \multirow[t]{2}{*}{ Other } & 8.7 & 8.9 & 10.2 & 15.1 & 11.9 & 7.6 & 8.1 & 9.1 & 9.3 & 6.5 & 9.3 & 13.0 \\
\hline & 100 & 100 & 100 & 100 & 100 & 100 & 100 & 100 & 100 & 100 & 100 & 100 \\
\hline \multicolumn{13}{|l|}{ Educ. attainment } \\
\hline PrimC & 28.2 & 51.3 & 35.4 & 43.1 & 32.3 & 25.6 & 32.6 & 48.4 & 28.1 & 44.5 & 39.4 & 21.1 \\
\hline LessP & 38.1 & 18.3 & 34.7 & 22.9 & 49.8 & 64.9 & 55.7 & 26.5 & 56.4 & 16.6 & 42.2 & 28.7 \\
\hline \multirow[t]{2}{*}{ SecoM } & 33.7 & 30.4 & 29.9 & 34.0 & 17.8 & 9.5 & 11.6 & 25.2 & 15.6 & 38.8 & 18.4 & 50.2 \\
\hline & 100 & 100 & 100 & 100 & 100 & 100 & 100 & 100 & 100 & 100 & 100 & 100 \\
\hline
\end{tabular}


Note: Proportions are weighted for representativeness. 
Table A2. Characteristics of young adults aged 20-25 who do (linked) and who do not live with their parents (not linked). Percentages, all countries pooled, for total population and by gender.

\begin{tabular}{lcccccc}
\hline & \multicolumn{2}{c}{ Total } & \multicolumn{2}{c}{ Women } & \multicolumn{2}{c}{ Men } \\
\hline & Linked & Not linked & Linked & Not linked & Linked & Not linked \\
\hline At school & 30.8 & 14.4 & 34.1 & 14.8 & 28.2 & 13.9 \\
Works & 59.3 & 58.9 & 49.5 & 41.9 & 67.3 & 82.0 \\
NiNi & 23.3 & 34.2 & 30.2 & 50.2 & 17.6 & 12.7 \\
Teenage parent & 6.7 & 27.3 & 11.9 & 35.3 & 2.4 & 16.4 \\
Young-adult parent & 6.8 & 26.1 & 9.9 & 26.1 & 4.2 & 26.2 \\
Married & 4.3 & 27.4 & 4.9 & 31.2 & 3.8 & 22.2 \\
In union & 7.3 & 44.5 & 6.9 & 46.2 & 7.6 & 42.3 \\
Education HH SecoM & 27.8 & 34.5 & 29.3 & 35.4 & 26.6 & 33.4 \\
Education HH LessP & 30.8 & 39.4 & 31.4 & 38.5 & 30.4 & 40.6 \\
Younger (aged 20-22) & 39.3 & 26.8 & 39.5 & 28.0 & 39.0 & 25.1 \\
Urban & 19.8 & 22.4 & 17.8 & 23.0 & 21.4 & 21.7 \\
Home owned & 83.4 & 57.7 & 82.9 & 59.3 & 83.7 & 55.5 \\
\hline Linked & \multicolumn{3}{c}{52.8} & 46.7 & & 59.2 \\
Upward mobility & 35.6 & 46.6 & & 29.0 \\
\hline
\end{tabular}

Note: Proportions are weighted for representativeness. HH- household head. 
Figure A1. Country-specific coefficients for models predicting the proportion of individuals in the "Attending school". Light gray markers indicate statistically insignificant differences with respect to the reference category in parenthesis. The intercepts are included next to the country names in the label.

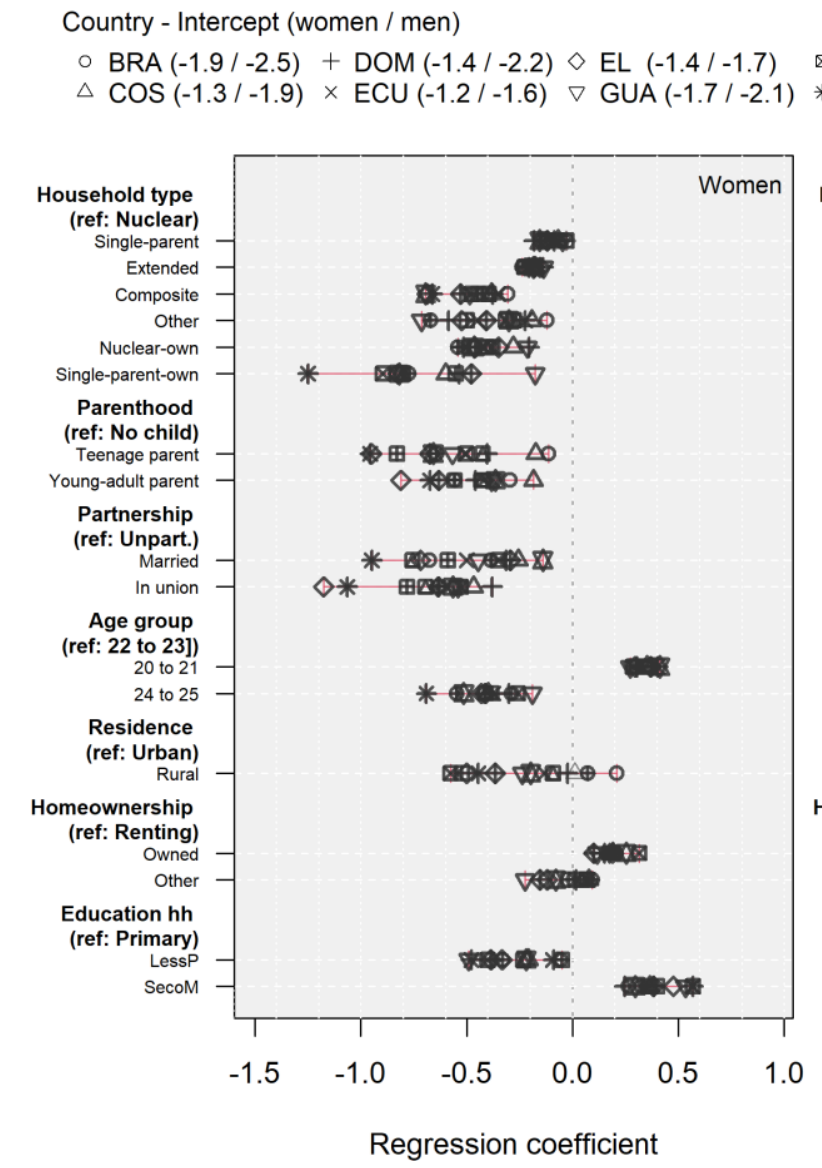

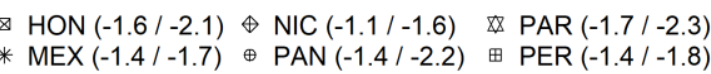

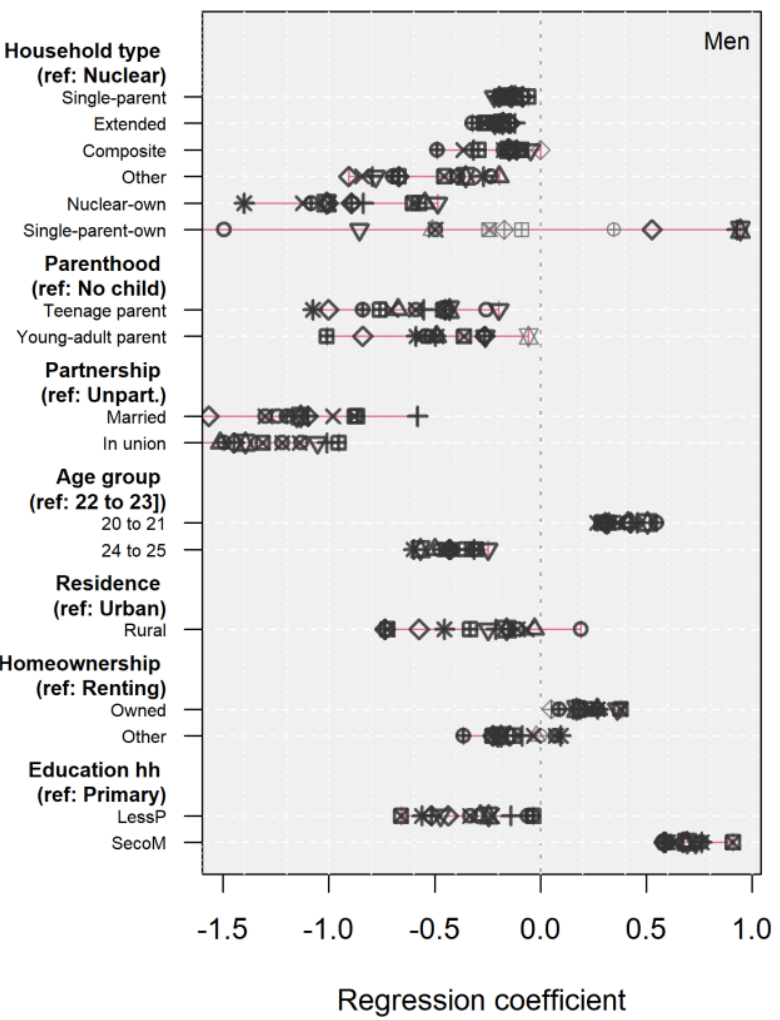

Note: We restrict the $\mathrm{x}$-axis to -1.5 to favor visibility. The coefficient below -1.5 correspond to Mexico (beta $=-2.76$ ), where the number of men in ' 'Single-parent-own' households is small, making the estimated coefficient erratic (standard errors $=0.378$ ). 
Figure A2. Predicted proportion of individuals in the 'Attending school' category by educational attainment of the household head.

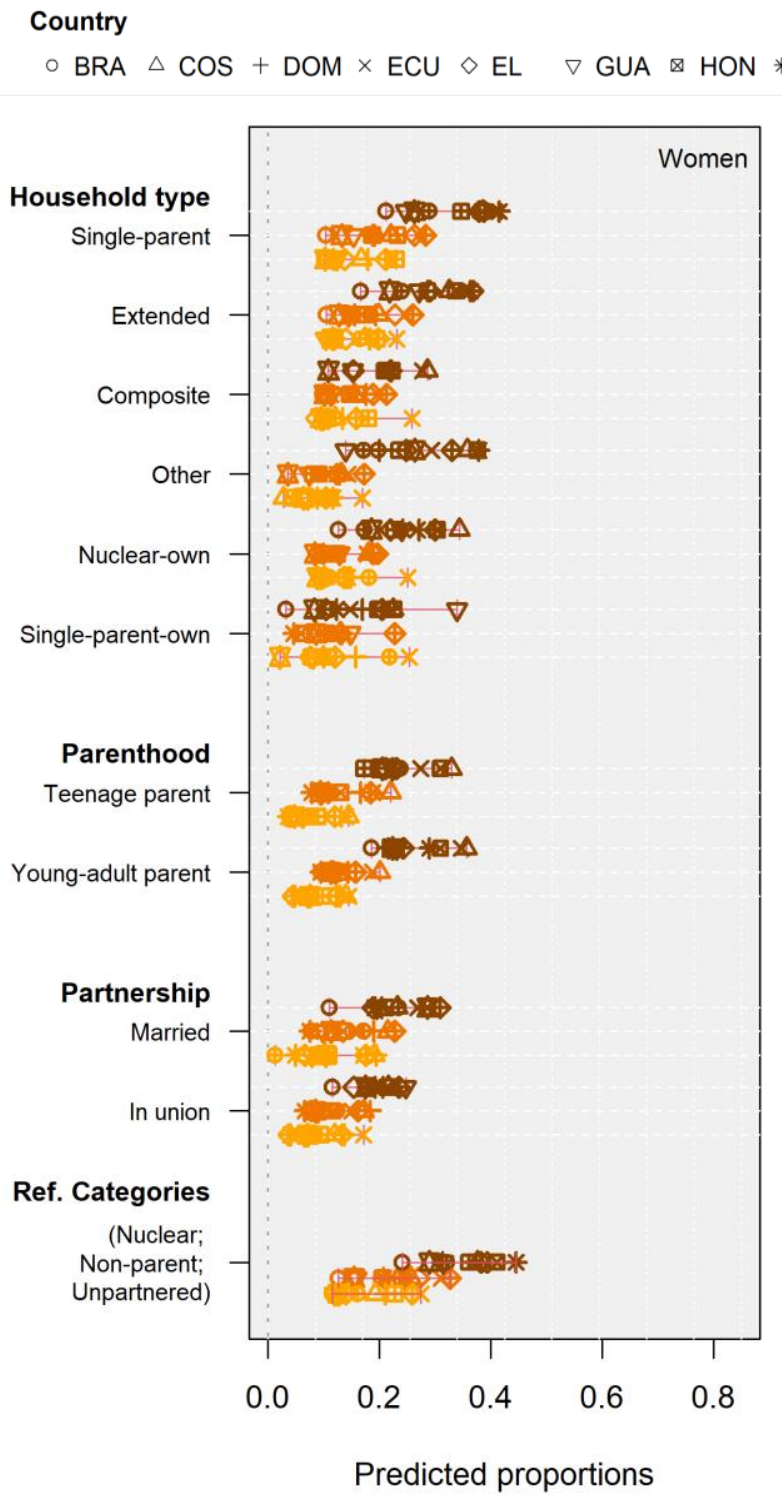

Less than primary
Primary completed

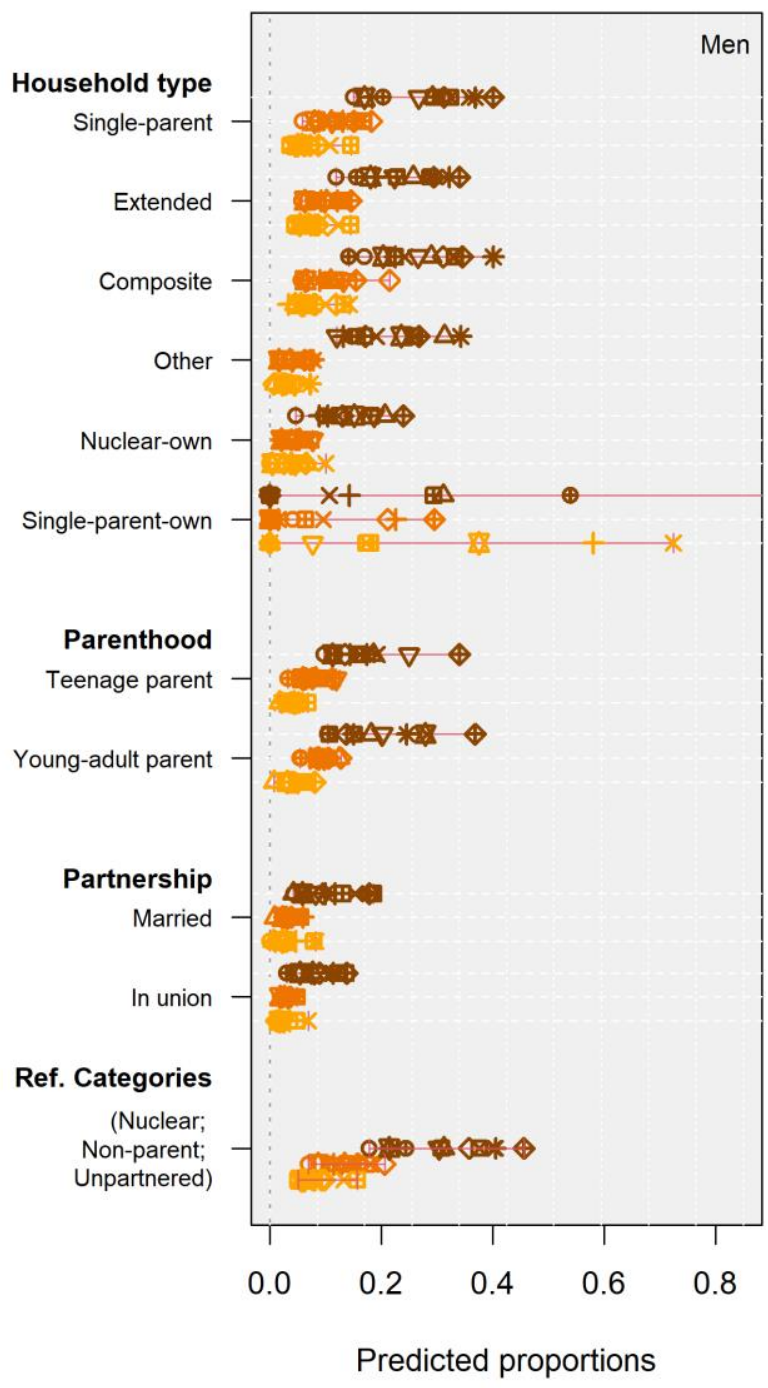

Secondary education or more

Note: Models were fitted separately for each of the three educational attainment level of the household head: Less than primary, Primary education completed, Some secondary education or more. Proportions are predicted for the reference category of each explanatory variable (Ref. Categories at the bottom). We restrict the $\mathrm{x}$-axis to 0.8 to favour visibility. 